Key Words:

curium

americium

decontamination

\title{
Final Report on the Demonstration of Disposal of Americium and Curium Legacy Material Through the High Level Waste System
}

\author{
T. B. Peters \\ D. T. Hobbs \\ D. P. Diprete \\ C. C. Diprete \\ S. D. Fink
}

January 16, 2002

Westinghouse Savannah River Company

Savannah River Site

Aiken, SC 29808

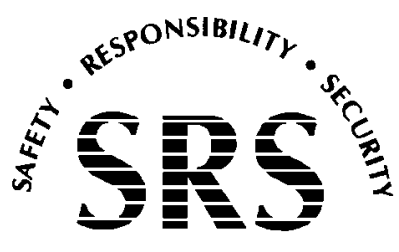

SAVANNAH RIVER SITE

Prepared for the U.S. Department of Energy Under

Contract Number DE-AC09-96SR18500 
This document was prepared in conjunction with work accomplished under Contract No. DEAC09-96SR18500 with the U.S. Department of Energy.

\section{DISCLAIMER}

This report was prepared as an account of work sponsored by an agency of the United States Government. Neither the United States Government nor any agency thereof, nor any of their employees, makes any warranty, express or implied, or assumes any legal liability or responsibility for the accuracy, completeness, or usefulness of any information, apparatus, product or process disclosed, or represents that its use would not infringe privately owned rights. Reference herein to any specific commercial product, process or service by trade name, trademark, manufacturer, or otherwise does not necessarily constitute or imply its endorsement, recommendation, or favoring by the United States Government or any agency thereof. The views and opinions of authors expressed herein do not necessarily state or reflect those of the United States Government or any agency thereof.

This report has been reproduced directly from the best available copy.

Available for sale to the public, in paper, from: U.S. Department of Commerce, National Technical Information Service, 5285 Port Royal Road, Springfield, VA 22161

phone: (800) 553-6847

fax: (703) 605-6900

email: orders@ntis.fedworld.gov

online ordering: http://www.ntis.gov/support/index.html

Available electronically at http://www.osti.gov/bridge

Available for a processing fee to U.S. Department of Energy and its contractors, in paper, from: U.S. Department of Energy, Office of Scientific and Technical Information, P.O. Box 62, Oak Ridge, TN 37831-0062

phone: (865)576-8401

fax: (865)576-5728

email: reports@adonis.osti.gov 
WSRC-TR-2002-00029

\section{Reviews and Approvals}

T. B. Peters, Task Leader

Date

Waste Processing Technology

D. T. Hobbs

Date

Waste Processing Technology

C. C. Diprete

Date

Analytical Development Section

D. P. Diprete

Date

Analytical Development Section

M. C. Thompson, Design Check

Date

Actinide Technology Section

S. D. Fink, Level 4 Manager,

Date

Waste Processing Technology

G. D. Thaxton

Date

Project Engineering Manager

S. A. Yano

NMMD Engineering

S. L. Tibrea

Date

HLW Waste Removal

R. E. Edwards

HLW Process Engineering

Date 
WSRC-TR-2002-00029

\section{List of Abbreviations and Conventions}

$\begin{array}{ll}\text { ADS } & \text { Analytical Development Section } \\ \mathrm{Am} & \text { Americium } \\ \mathrm{Cm} & \text { Curium } \\ \mathrm{DF} & \text { Decontamination Factor (= starting concentration/ending concentration) } \\ \mathrm{DU} & \text { Depleted Uranium } \\ \text { DWPF } & \text { Defense Waste Processing Facility } \\ \mathrm{HLW} & \text { High Level Waste } \\ \mathrm{ICP}^{-E S} & \text { Inductively Coupled Plasma Electro Spray } \\ \mathrm{ICP}^{-M S} & \text { Inductively Coupled Plasma Mass Spectroscopy } \\ \mathrm{MnO}_{4}^{-} & \text {Permanganate } \\ \text { MST } & \text { Monosodium Titanate } \\ \text { NaOH } & \text { Sodium Hydroxide } \\ \text { neutralized } & \text { used interchangeably with "caustic added" } \\ \text { Np } & \text { Neptunium } \\ \text { Pu } & \text { Plutonium } \\ \text { SRTC } & \text { Savannah River Technology Center } \\ \text { U } & \text { Uranium } \\ \text { WPTS } & \text { Waste Processing Technology Section }\end{array}$


WSRC-TR-2002-00029

\subsection{Executive Summary}

This report provides the results of experimental demonstrations related to processing of a legacy solution containing americium and curium through the High Level Waste (HLW) system. The testing included eight experiments covering the baseline, mitigation, and enhanced nitrate processing studies. In general, each experiment studied the mixtures generated over a period of time to emulate the lifecycle of actual sludge in the High Level Waste system. While the data in previous reports remain valid, this report supercedes all the previous reports and provides a collective overview of the work.

Upon addition of caustic and sodium nitrate to the legacy solution, the vast majority (i.e., $99.99 \%+$ as determined by ICP-MS) of the curium precipitates from solution.

Immediatey after caustic addition, radiochemical analysis indicates that the remaining supernatant liquid possesses sufficient alpha activity to require further reductions in the total concentration of alpha emitters to meet Saltstone requirements. The amount of additional decontamination needed varies slightly with each variation in each of the proposed flowsheets. Following treatment of the caustic-added slurry in the same manner as planned for the actual HLW sludge, the supernatant liquids in the two "baseline" experiments fall within the Saltstone total alpha limit of $18 \mathrm{nCi} / \mathrm{g}$. A third demonstration (Experiment \#8) added extra nitrate to reduce hydrogen generation by radiolysis. The final solution from this experiment met Saltstone requirements. The remaining demonstrations produced a final solution that required an additional $\sim 2 \mathrm{x}$ reduction in total alpha activity to meet process requirements. We observed that depleted uranium provided a benefit for alpha removal.

These results provide a conservative measure of expected performance. While both high and low biases exist in our study, the net bias gives conservatively high values for measured alpha activity. Evaluation of the source of analytical biases suggests the measured values may prove $4 \mathrm{x}$ higher than the actual content. Furthermore, the laboratory demonstrations used less dilution than expected in the transfer of the slurry into Tank $51 \mathrm{H}$. This offset in dilution results in a high bias of $\sim 5 \mathrm{x}$ or more in the measured alpha activity relative to expected operations. Also, additional dilution - that we can not estimate at this time - will also occur during transfer of the supernatant liquid through the evaporator system and through the Salt Waste Processing Facility.

Finally, long term monitoring of samples pulled at various stages of the slurry treatment indicate continued decline in total activity suggesting actual processing performance may exceed expectations from these tests.

As a result of these experiments, SRTC recommends using the baseline process or the enhanced nitrate process as the flowsheet of choice. 
WSRC-TR-2002-00029

\subsection{Introduction}

Tank 17.1 in F-Canyon contains an americium and curium $(\mathrm{Am} / \mathrm{Cm})$ bearing solution. The Am/Cm components of this solution resulted from the MARK-40 and MARK-41 campaigns during the mid/late 70's. ${ }^{1}$ Since 1984 , no further additions to Tank 17.1 occurred except to replace evaporative and acid losses. ${ }^{2}$ In 1993, the Department of Energy requested Westinghouse Savannah River Company to evaluate proposed disposition options and provide a recommended disposition option. ${ }^{3}$ More recently, an evaluation identified the most cost-effective method as discarding this material directly to the High Level Waste tanks. ${ }^{4}$ However, a recent risk assessment identified a primary risk of this method as the potential dissolution of curium into solution, where it could impact several HLW processes. ${ }^{¥}$ Given the high specific activity $(80.9 \mathrm{Ci} / \mathrm{g})^{\vartheta}$ and energy of ${ }^{244} \mathrm{Cm}$ emitted alpha particle (5.8 MeV/discharge), the soluble curium concentration during the disposal process proves key in determining whether the resultant waste meets disposal requirements. Limited data exists on curium solubility in highly alkaline solutions. ${ }^{5,6,7,8}$ Equally large discards of curium and americium occurred earlier on site, but little reliable monitoring occurred to track the fate of the material in the waste tanks. Encouragingly, the curium content of the supernatant liquid in Tank $39 \mathrm{H}$ - which received a large curium transfer - does not require additional curium removal to meet processing criteria. (See Appendix I for a brief overview of the historical discards.) Given the limited data available on the fate of such material transfers, the program required additional experimental measurements. ${ }^{9}$

\subsection{Experimental Detail}

Figure 1 provides a schematic of the proposed general disposal path for the legacy solution. The baseline proposal dilutes the solution by adding depleted uranium to help comply with Waste Acceptance Criteria ${ }^{10,11}$ for the tank farm. Addition of $50 \mathrm{wt} \%$ $\mathrm{NaOH}$ solution and dilution water occurs in sufficient volume to produce a resultant slurry with $>1.0 \mathrm{M}$ free hydroxide. Personnel will transfer the slurry first to F-Tank Farm and then to Tank $51 \mathrm{H}$ via an interarea transfer line. "Inhibited water" (i.e., $0.01 \mathrm{M} \mathrm{NaOH}$ solution) and sludge from Tank $7 \mathrm{~F}$ will follow or accompany the transfers to help scour the high activity solids from the transfer piping.

\footnotetext{
$¥$ While the americium-243 present also represents a source term danger, the dose proves small in comparison to that of curium-244 present.

${ }^{\vartheta}$ Some previous documents use a different specific activity, quoted from a different reference. For consistency, we now use all specific activities from one single reference (DOE/RW-0006, Rev 7).
} 


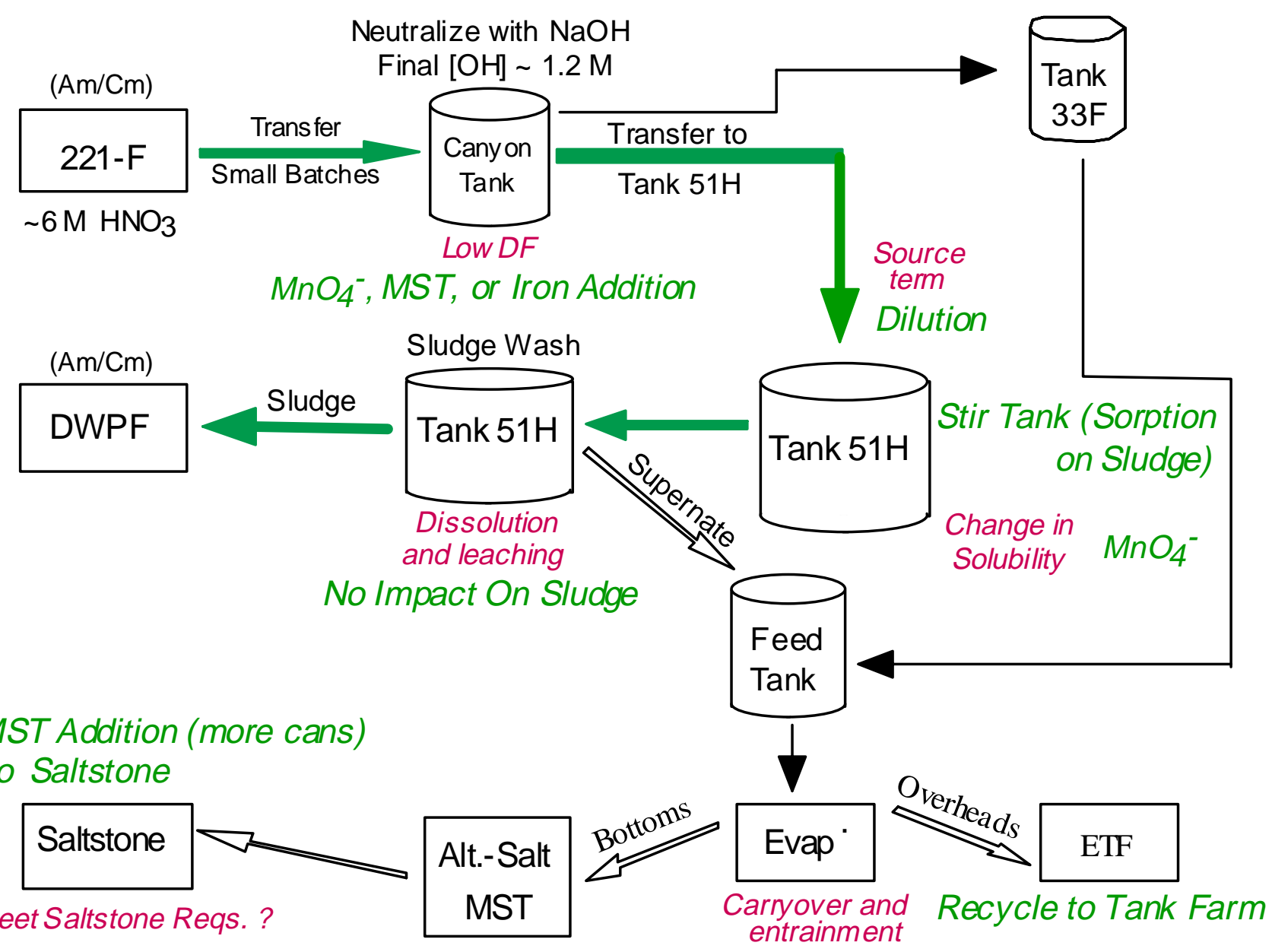

Figure 1. Proposed path for disposal of legacy material in Tank 17.1 of Building 221-F. The experiments of this demonstration examine the proposed path plus a number of variants. The red text indicates potential problems, while the green text indicates potential solutions to those problems. 
After holding the waste in Tank $51 \mathrm{H}$ for some period, personnel will wash the sludge contained in Tank 51H to meet the requirements for feed material to the Defense Waste Processing Facility (DWPF). ${ }^{12}$ Decanted liquid and wash water will pass through an evaporator after mixing with supernatant waste in an as yet unidentified tank. Eventually, the decanted liquid will pass through the Salt Waste Processing Facility with treatment by addition of monosodium titanate (MST) to remove soluble strontium and radionuclides that emit alpha radiation. Disposition of the washed solids in Tank $51 \mathrm{H}$ occurs via vitrification in DWPF.

In addition to demonstrating the baseline process, these experiments also examine a number of possible variants to the chemistry. Figure 1 lists the experiments that comprise this study. Experiment \#3 examines the benefit of omitting the depleted uranium, and provides a closer match to experimental conditions done in previous curium work by Hobbs. ${ }^{6}$ Experiments \#4 and \#5 examine the benefit of adding either sodium permanganate (with formate as a reducing agent) or MST following the initial neutralization of the solution from Tank 17.1. Previous studies with Hanford waste suggests that permanganate acts efficiently to remove actinides from salt slurries. ${ }^{7,8}$ The Salt Processing Project proposes use of MST to remove actinides from salt slurries. ${ }^{13}$ Addition of small amounts of MST after neutralization may yield increased removal efficiency for the actinides prior to transfer of the slurry to the tank farms. Experiment \#6 studies the effect of replacing the depleted uranium solution with a ferric nitrate

\begin{tabular}{|c|l|}
\hline Experiment \# & \multicolumn{1}{|c|}{ Description } \\
\hline $1 \& 2$ & Baseline treatment process \\
\hline 3 & $\begin{array}{l}\text { Baseline treatment process omitting } \\
\text { addition of depleted uranium }\end{array}$ \\
\hline 4 & $\begin{array}{l}\text { Baseline treatment with addition of sodium } \\
\text { permanganate and formate after } \\
\text { neutralization }\end{array}$ \\
\hline 5 & $\begin{array}{l}\text { Baseline treatment with addition of MST } \\
\text { after neutralization }\end{array}$ \\
\hline 6 & $\begin{array}{l}\text { Baseline treatment with addition of } \\
\text { ferric nitrate in lieu of depleted uranium }\end{array}$ \\
\hline 7 & $\begin{array}{l}\text { Dilution of neutralized slurry from baseline } \\
\text { process (Experiment 1) by 5:1 volume } \\
\text { addition of 0.01 M NaOH solution }\end{array}$ \\
\hline 8 & $\begin{array}{l}\text { Baseline treatment process, with added } \\
\text { sodium nitrate }\end{array}$ \\
\hline & \\
\hline
\end{tabular}

Table 1. List of experiments. 
slurry. Experiment \#7 dilutes a portion of the neutralized slurry from Experiment \#1; this experiment provided early insight for any immediate leaching of the precipitated actinides. Finally, Experiment \#8 examines the effect of increasing the nitrate concentration by added $\mathrm{NaNO}_{3}$. Use of increased nitrate content reduces radiolytic generation of hydrogen. ${ }^{14}$

In our experiments, the researchers made a reasonable attempt to simulate the HLW "lifecycle" of the Am/Cm sludge. All of the tests except Experiment \#7 followed the same general procedure and order:

- addition of caustic to the acidic Am/Cm solution,

- addition of a Tank $51 \mathrm{H}$ surrogate slurry,

- decant of the supernatant liquid and washing the sludge, and

- combining the decants and washes with an MST treatment of the composite.

\subsection{Caustic Addition to the Am/Cm Solution}

Using the same addition recipe ${ }^{15}$ as proposed for canyon operations, the researchers added caustic (in the form of $50 \mathrm{wt} \% \mathrm{NaOH}^{\#}$ ), water (tap water), and other ingredients (e.g., depleted uranium (DU), $\mathrm{NaMnO}_{4}, \mathrm{MST}$, etc) as necessary to generate a caustic sludge. This caused the majority of the dissolved metals to precipitate as metal hydroxides. Over a relatively short amount of time (i.e., within hours), the solids would settle from the slurry. Once generated, we allowed the caustic slurry to sit undisturbed except when withdrawing a portion for the next step in the process (i.e., "Aging").

\subsection{Addition of Tank 51H Surrogate ("Aging")}

During disposal, personnel will transfer the Am/Cm slurry to Tank $51 \mathrm{H}$, where it will mix with the contents of other tanks. After mixing the slurry will remain in Tank $51 \mathrm{H}$ for approximately 4 years not including the time the heel material requires for processing. ${ }^{16}$ We lacked samples from Tanks 7F, 18F, and 19F to provide an accurate sludge mixture representing the expected contents of Tank $51 \mathrm{H}$ at this time. However, since minor variations in the bulk sludge composition will not likely cause major shifts in the ability to sorb or trap the actinides, we used a multi-tank composite present in the workplace in sufficient quantities. Appendix II contains analyses on the multi-tank composite (referred to from now on as MTC\#1). As this material has a supernatant liquid activity significantly greater than that of the $\mathrm{Am} / \mathrm{Cm}$ supernatant liquid, we would expect that there be no large dilution effect from adding the multi-tank composite.

Experiments \#1-6 consumed the multi-tank composite of sludge. For Experiment \#8, we acquired another multi-tank composite (now on referred to from now on as MTC \#2). Appendix III contains the results of the compositional analysis of this material. However,

\footnotetext{
\# The rayon grade caustic solution was analyzed as received. The carbonate level was found to be $<0.02 \mathrm{M}$ (detection limits).
} 
the same analytical uncertainty that affects the $\mathrm{Am} / \mathrm{Cm}$ samples also applies to these composite materials, so the total alpha activities are an upper bound.

We removed a portion of the Am/Cm caustic slurry and mixed with enough of the Tank $51 \mathrm{H}$ surrogate so that the ratio of the mass of solids present in the Am/Cm caustic slurry to the mass of the solids in the Tank 51H surrogate equaled 1:20. In the HLW waste tanks, the anticipated solids ratio equals $\sim 1: 100$. Hence, this study provides about a 5fold conservatism with respect to dilution of solids. The approximate liquid dilution (this varies from experiment to experiment) equaled $\sim 1.5$ across all the experiments. After adding the Tank $51 \mathrm{H}$ surrogate, we also added a small amount of a solution containing $\mathrm{NaNO}_{3}, \mathrm{NaNO}_{2}, \mathrm{Na}_{2} \mathrm{CO}_{3}$ so as produce a final supernatant liquid estimated to be similar to Tank 51H. Appendix IV lists the exact slurry composition for each experiment. Personnel thoroughly agitated this mixture and then allowed it to settle. For the following four weeks, operators collected a supernatant liquid sample once per week.

\subsection{Decant and Sludge Washing (Extended Sludge Processing)}

Prior to transfer of the sludge to DWPF, the process includes decanting the supernatant liquid from Tank $51 \mathrm{H}$ and washing the remaining sludge until the sodium content of the wash reaches $\sim 0.5 \mathrm{M}$. For these experiments, we estimated that decanting the supernatant liquid, followed by three washes using inhibited water $(0.01 \mathrm{M} \mathrm{NaOH})$ would drive the wash sodium levels to $\sim 0.5 \mathrm{M}$. Each wash solution consisted of a volume of $1.5 x$ the remaining slurry volume. Removal of the supernatant liquid occurred by a careful decant of the settled slurry, followed by the use of slurry pipettes to remove the rest of the overlaying liquid. A small amount of sludge was entrained in the decanted solution. Solids were also entrained in the decanted supernate taken for HLW tanks. Personnel sampled and segregated each of the decant and wash solutions.

\subsection{MST Treatment on the Decant and Wash Composite (Salt Waste Processing)} To reduce the total alpha (actinide) concentration to levels acceptable to Saltstone, the planned Salt Waste Processing will use MST to sorb the actinides. Personnel mixed this composite solution of the wash water and decanted liquid. This composite was mixed with a salt solution to increase the sodium levels to $5.6 \mathrm{M}{ }^{\nabla}$ We treated this composite with $0.4 \mathrm{~g} / \mathrm{L}$ of MST, and sampled the resulting supernatant liquids at $24 \mathrm{~h}$ and 1 week after the treatment. The 24-hour sample is the most meaningful data point of the two as that sampling time agrees with the proposed cycle time for the facility.

During actual processing, the wash water and decanted solution will likely pass through an evaporator with blending among other salt solutions. The evaporator may produce saltcake or may simply act as a concentrating step depending on mode of operation at that

\footnotetext{
$\nabla$ The salt solution contained 1 part 39 wt $\% \mathrm{NaNO}_{2}, 5$ parts $40 \mathrm{wt} \% \mathrm{NaNO}_{3}$, and 1.6 parts $50 \mathrm{wt} \%$ $\mathrm{NaOH}$. This solution measured $8.95 \mathrm{M}$ in sodium and we mixed it with the $\mathrm{Am} / \mathrm{Cm}$ wash/decant composite to generate a new composite containing 5.6 M sodium. This dilution substituted for the feed preparation planned for the Salt Waste Processing Facility.
} 
WSRC-TR-2002-00029

time. A reliable definition of the future blending strategy for the supernate does not exist. However, it seems extremely likely that the actinide content of the Am/Cm material in Tank $51 \mathrm{H}$ will actually receive dilution across several batches to the Salt Waste Processing Facility. We believe the testing added an additional conservatism with regard to actinide removal by this simplification but we can not accurately quantify the impact.

\subsection{Sampling Procedures}

All sampling of the supernatant liquids used a single protocol. First, operators allowed the slurry to settle to avoid transfer of solid particles into the sample. Then, the operator pulled a liquid sample using a $10 \mathrm{~mL}$ plastic syringe and filtered this aliquot through a $0.2 \mu \mathrm{m}$ (pore-size) nylon syringe filter into analytical sample bottles.

\subsection{Results of Investigations}

F-Canyon Operations personnel provided $100 \mathrm{~mL}$ of Tank 17.1 solution to SRTC for the investigations. Appendix V contains a complete set of data on this material.

The overall objective of the process involves removing alpha emitting radionuclides below the Saltstone limits of $18 \mathrm{nCi} / \mathrm{g}$. For this reason, this report deals mainly in terms of total alpha activities, instead of curium concentrations. Appendix VI contains a tabulated set of data for the results of each of the experiments.

\subsection{Analytical Limitations}

The processed solutions used in these experiments represent a challenge to the radiochemical counting methods for three reasons: low curium concentration, high salt content, and high gamma activity relative to alpha activity. The high salt content interferes in getting consistent readings of curium by counting methods. Gross alpha/alpha pulse height analysis measurements on the $\mathrm{Am} / \mathrm{Cm}$ supernatant solutions showed significant variance for several reasons. The elevated salt concentrations of the sample solutions made direct sample mounting on the stainless steel planchets difficult as the flaming process used to fix the alpha activity on the counting planchets works best for solutions of low dissolved salt. The solids on the sample mounts also attenuate the alpha emissions to varying degrees which results in degraded alpha spectra, reducing the accuracy of the determinations of the various alpha-emitting constituents in the samples. In some cases, the samples contained enough beta activity relative to alpha activity that the small percentage of beta events misidentified as alpha events in the gross alpha gas flow proportional counting analysis biased the observed activity high. At this time, the data we have indicates the bias as $\sim 4.5 \mathrm{x}$ high. However we conservatively use the data as reported. Appendix VII lists the test data we used to quantify this bias. 
WSRC-TR-2002-00029

When available, we used inductively coupled plasma mass spectroscopy (ICP-MS) data to confirm the counting methods. The high salt content also necessitates larger sample dilutions during ICP-MS to avoid plating of the salts on the equipment. The larger dilutions reduce the concentration of trace elements in the sample to below detection limits. Many of the curium determinations fell below the detection limit for this method.

Throughout the main body of this report, unless otherwise noted, we report the data from radio counting techniques, which exhibit a superior detection limit for ${ }^{244} \mathrm{Cm}$ than ICPMS. The appendices contain the ICP-MS data.

Finally, during the final stages of this work, one of our quality assurance checks discovered that the polyethylene bottles used in our sampling routines sorbed curium from the solution after prolonged exposure to the sample. This would mean the curium results (and we will infer total alpha results, too) may have a low bias. The data shows a $1.15 x$ low bias for extended exposure of the sample for $\sim 8$ weeks. This bias remains less than the conservatism in the demonstration due to sample dilutions. Appendix VII lists some of the test data we used to make this determination.

\subsection{Baseline Process (Experiment \#1 and \#2)}

Experiment \#1 and \#2 ("Baseline experiments") followed the proposed baseline process. These experiments served as duplicates of each other, and both used the following recipe. ${ }^{15}$

9.40 $\mathrm{mL}$ of depleted uranium solution $\left(350 \mathrm{~g} / \mathrm{L}\right.$ of $\left.{ }^{238} \mathrm{U}\right)$

13.0 $\mathrm{mL}$ of Tank 17.1 solution

$17.4 \mathrm{~mL}$ of 50 wt $\% \mathrm{NaOH}$ solution

91.4 $\mathrm{mL}$ of process water

The resulting tan caustic slurry settled within a few hours. Throughout the entire experimental sequence, we obtained eight data points. Figure 2 shows the total alpha activity (nCi/g) for Experiments \#1, \#2 and the simple average of the two, while Table 2 shows the numerical data. We present the decant and wash data as a volume adjusted composite value and not as separate data points, since we treated the composite with MST in the next step of the demonstration. Between the neutralization (caustic slurry) and Aging \#1 data points, a slight increase in activity occurred in Experiment \#1. In fact, if one examines all seven of the demonstrations of the full disposal steps, four (\#1, \#4, \#5, \#6) show an increase in activity from the neutralized to aged step, while three (\#2, \#3, \#8) show a decrease. 
WSRC-TR-2002-00029

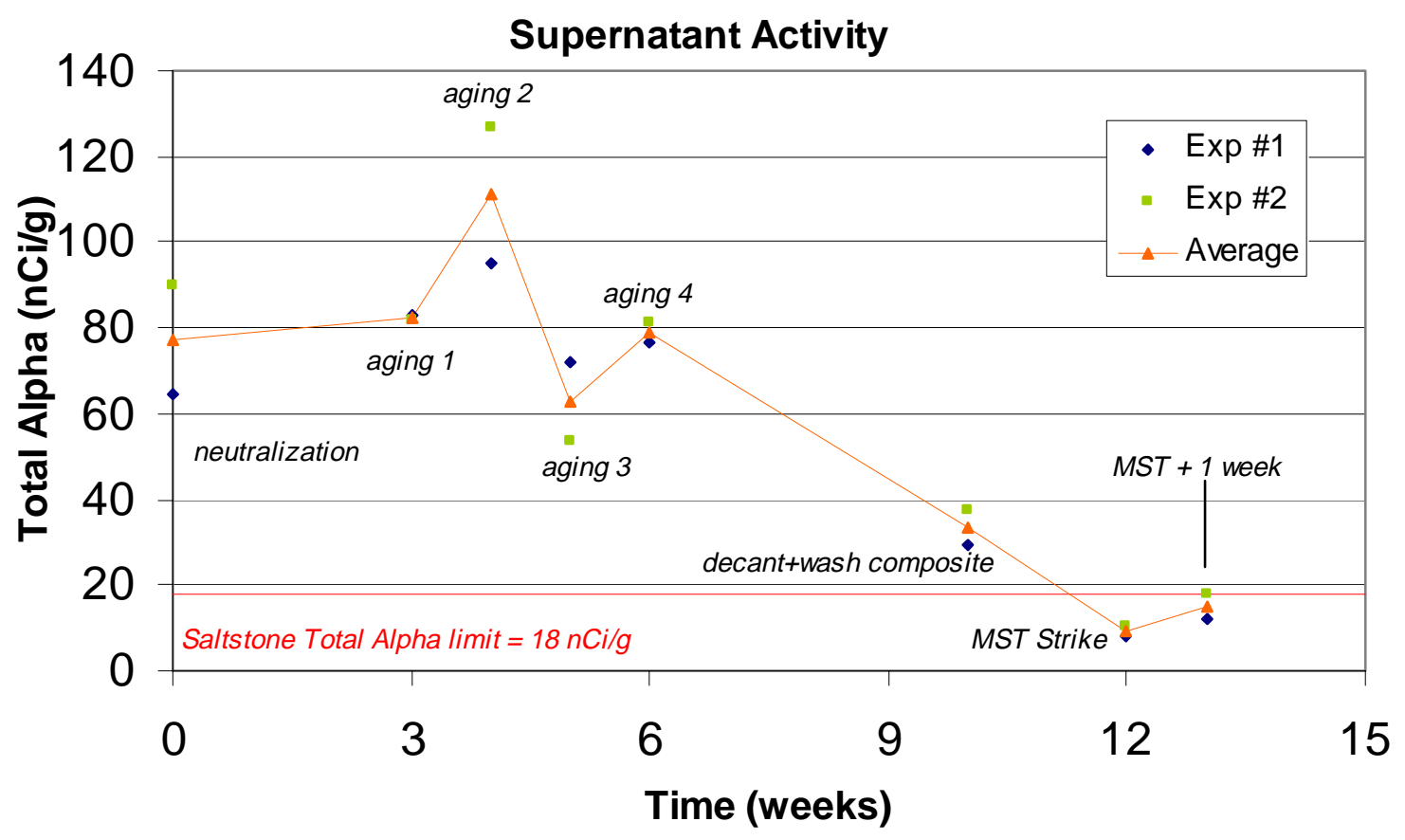

Figure 2. Total Alpha Activity Over Time for Baseline Experiments.

\begin{tabular}{|l|c|c|c|c|}
\hline & & \multicolumn{3}{|c|}{ Activity (nCi/g) } \\
\hline \multicolumn{1}{|c|}{ Data Point } & Time (weeks) & Experiment \#1 & Experiment \#2 & Simple Average \\
\hline original soln. & /-/ & $1.17 \mathrm{E}+07$ & $1.17 \mathrm{E}+07$ & $1.17 \mathrm{E}+07$ \\
\hline caustic slurry & 0 & 64.7 & 89.7 & 77.2 \\
\hline Aging 1 & 3 & 83.1 & 81.9 & 82.5 \\
\hline Aging 2 & 4 & 95.0 & 127 & 111 \\
\hline Aging 3 & 5 & 72.1 & 53.6 & 62.9 \\
\hline Aging 4 & 6 & 76.6 & 81.1 & 78.9 \\
\hline $\begin{array}{l}\text { decant+wash } \\
\text { composite }\end{array}$ & 10 & 29.6 & 37.3 & 33.5 \\
\hline MST 1 & 12 & 8.35 & 10.1 & 9.23 \\
\hline MST 2 & 13 & 11.9 & 17.6 & 14.8 \\
\hline
\end{tabular}

Table 2. Numerical Data for Baseline Experiments.

Since we know the total alpha activity of both the $\mathrm{Am} / \mathrm{Cm}$ supernatant liquids and the Tank 51H surrogate, we can estimate the activity of the mixed composite. Table 3 lists the total alpha activities of the neutralized $\mathrm{Am} / \mathrm{Cm}$ slurries, as well as the activity of the Tank 51H surrogate (MTC \#1) and the estimated and measured activities of their respective composites (i.e., the "Aging 1" data). The activity for the theoretical mix point far exceeds the measured activity, suggesting additional decontamination occurred after 
WSRC-TR-2002-00029

\begin{tabular}{|l|c|}
\hline \multicolumn{1}{|c|}{ Supernatant Liquid } & Total Alpha Activity (nCi/g) \\
\hline Experiment \#1 & 64.7 \\
\hline Experiment \#2 & 89.7 \\
\hline MTC \#1 & 753 \\
\hline Exp \#1 + MTC \#1 estimate & 450 \\
\hline Exp \#1 + MTC \#1 measured & 83.1 \\
\hline Exp \#2 + MTC \#1 estimate & 458 \\
\hline Exp \#2 + MTC \#1 measured & 81.9 \\
\hline
\end{tabular}

\section{Table 3. Estimated and Measured Activities of the Neutralized and Aged Slurries}

combining the two slurries. However, activities of the MTC \#1+Am/Cm slurries contain a high bias due to the cesium content. Hence, the magnitude of additional decontamination achieved, if any, proves difficult to assess.

The following Aging data points stay approximately the same as the first aging sample, with no significant change in the total alpha activity over the four week period. Whatever dilution, leaching, or adsorption effects occur approximately cancel each other out.

After the aging step, the researchers decanted the supernatant liquids, and then washed the sludge three times with inhibited water. While we sampled and analyzed each of the decants and washes for total alpha activity, we present the data in this stage as a volume adjusted average. The original supernatant liquid from the aging process (i.e., the decant) underwent a $\sim 6 \mathrm{x}$ dilution (averaged across the two baseline experiments) during the washing process. We calculate this dilution as the volume of the decant divided by the total supernatant liquid volume removed during the decants and washes. The dilution was different for each experiment, and varied from $2.3 \mathrm{x}$ to $11 \mathrm{x}$. This does not represent a process limit, but simply the range of dilutions we encountered. Table 4 shows the data

\begin{tabular}{|c|c|c|}
\hline \multirow{2}{*}{ Process } & \multicolumn{2}{|c|}{ Total Alpha Activity (nCi/g) } \\
\cline { 2 - 3 } & Experiment \#1 & Experiment \#2 \\
\hline Decant & 70.0 & 97.5 \\
\hline Wash 1 & 27.4 & 21.9 \\
\hline Wash 2 & 28.4 & 32.5 \\
\hline Wash 3 & 12.0 & 16.3 \\
\hline $\begin{array}{c}\text { Decant/Wash } \\
\text { Composite }\end{array}$ & 29.6 & 37.3 \\
\hline Overall Decline & $\mathbf{2 . 3 6 x}$ & $\mathbf{2 . 6 1 x}$ \\
\hline
\end{tabular}

Table 4. Total Alpha Activity of the Decant and Washes for the Baseline Experiments. 
for each of the decant and washes for the baseline experiments. The overall decline in activity compares the decant activity to the composite activity. This data indicates that of all effects from leaching, dilution, and aging, the decline in total alpha activity equals less than half that expected from the effective dilution introduced during this step. This is not surprising, as one would expect adding a diluent would allow some more solid curium compounds to dissolve. This finding indicates some actinides leach into solution, but the dilution overwhelms the increase from leaching.

Finally, during the MST treatment step, the researchers took the decant/wash composite from the previous step and mixed it with a salt solution (see footnote, page 10) to generate a new composite. The effective dilution from adding the salt solution averaged $\sim 2.2$ across the two baseline experiments. Researchers combined this new composite solution with $0.4 \mathrm{~g} / \mathrm{L}$ of MST and removed samples from the resulting slurry at 24 hours and 1 week. Results of the MST treatment on the new composite showed a decline in activity, putting the total alpha below the Saltstone limits. Table 5 lists the total alpha activity of the decant/wash composite before and after the MST treatment

\begin{tabular}{|c|c|c|}
\hline \multirow{2}{*}{ Process } & \multicolumn{2}{|c|}{ Total Alpha Activity (nCi/g) } \\
\cline { 2 - 3 } & Experiment \#1 & Experiment \#2 \\
\hline $\begin{array}{c}\text { Decant/Wash } \\
\text { Composite }\end{array}$ & 29.6 & 37.3 \\
\hline MST 1 & 8.35 & 10.0 \\
\hline MST 2 & 11.9 & 17.6 \\
\hline 24 hour decline & $\mathbf{3 . 5 4 x}$ & $\mathbf{3 . 7 3 x}$ \\
\hline
\end{tabular}

MST 1 represents the data point taken 24 hours after the MST strike. MST 2 provides the data point taken 1 week after the MST strike.

\section{Table 5. Total Alpha Activity Before and After MST Treatment in the Baseline Experiments.}

for the baseline experiments. The data indicates some effective benefit to the MST treatment.

After each of the previous steps (caustic addition, aging, decant/washing, and MST treatment), the remaining material was saved and sampled periodically. The data from these samples is referred to as the "long term" data. We used this data to look for any significant long term negative trends. Figure 3 shows the graph of the long-term data, as well as some of the previously reported data as comparisons. In the case of the caustic slurry (neutralized), we see no significant variance. Over 20 weeks, the activity of the 
WSRC-TR-2002-00029

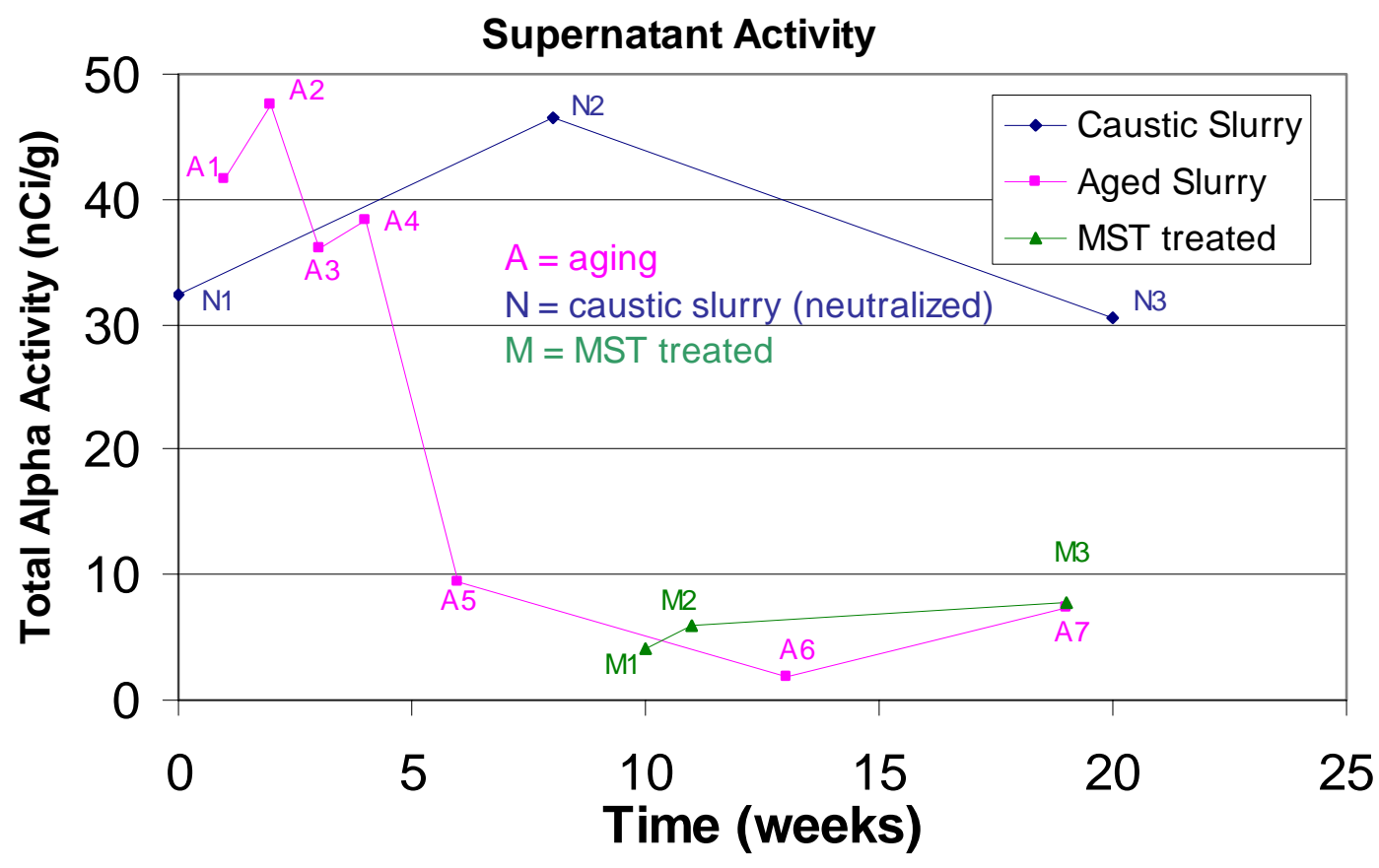

Figure 3. Long Term Data for the Baseline Experiment Average.

caustic added slurry remains relatively static. It is interesting to note that 5 of the 6 experiments (all except \#3) seem to show this pattern of an initial rise in activity, followed by a decline. In the case of the aged slurry, we see a fairly large decline by five weeks (the fifth week being the first of the long-term data points). We also see this pattern in all of the experiments, except for \#3. In the case of the MST treatment data we see a slight increase in the activity. About half the experiments see this slight increase, and the other half stay about the same or see a decline. This leads us to believe that there is no significant variance for the MST treated supernatant liquid.

\subsection{Baseline without Depleted Uranium (Experiment \#3)}

Experiment \#3 ("No DU experiment") repeated the baseline process omitting the addition of depleted uranium. This experiment used the following recipe.

\section{$13 \mathrm{~mL}$ of Tank 17.1 solution}

$17.4 \mathrm{~mL}$ of $50 \mathrm{wt} \% \mathrm{NaOH}$ solution

94.1 $\mathrm{mL}$ of process water

The resulting brown caustic slurry settled in the space of a few hours. Figure 4 shows a graph comparing the baseline average to the Experiment \#3 data set while Table 6 lists the numerical data for both. We present the decant and wash data as a volume adjusted composite value and not as separate data points. See Figure 5 for a visual comparison of the caustic slurries from the first three experiments. 
WSRC-TR-2002-00029

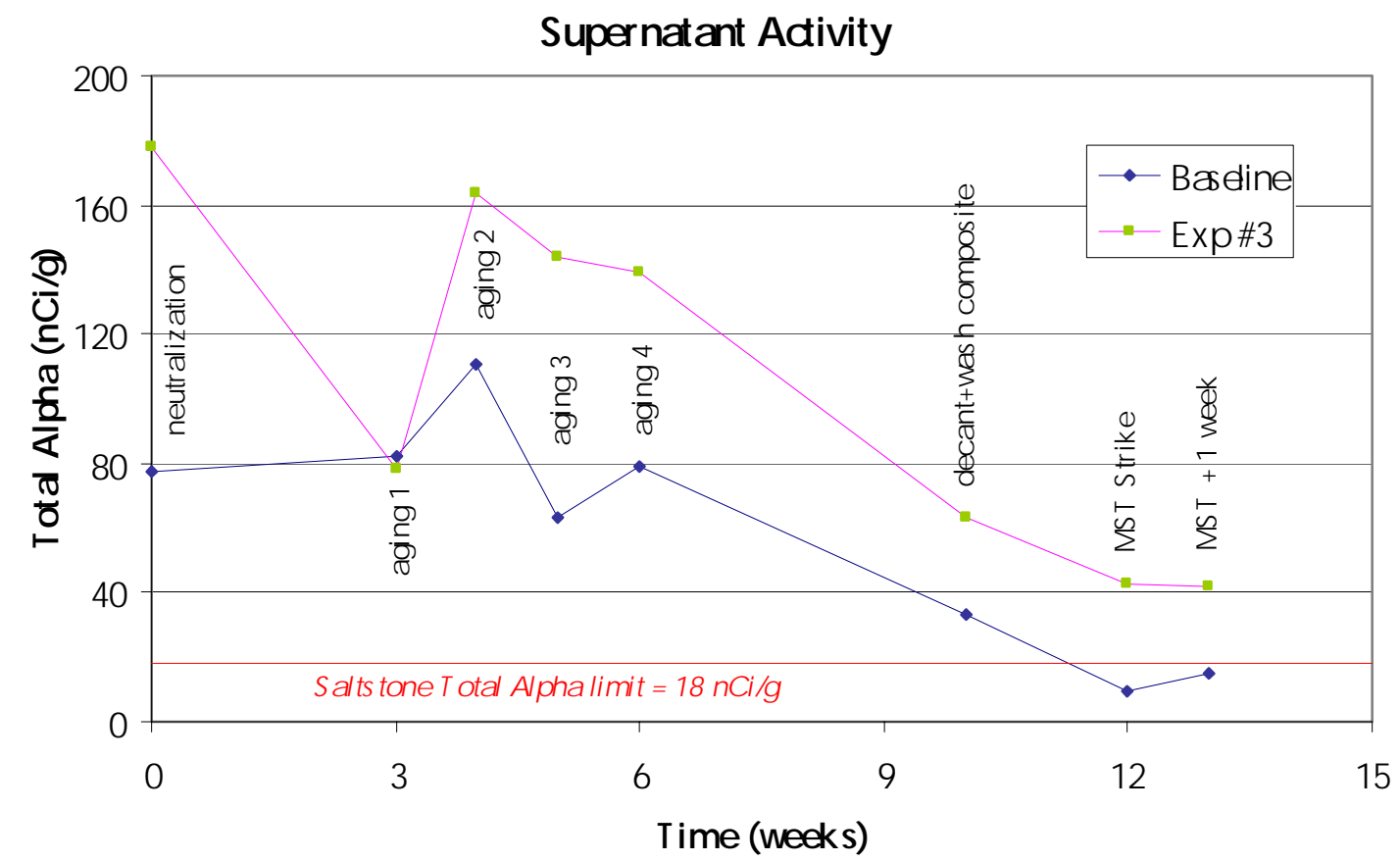

Figure 4. Comparison of No DU to the Baseline Average

\begin{tabular}{|l|c|c|c|}
\hline \multirow{2}{*}{ Data Point } & Time (weeks) & Activity (nCi/g) & Activity (nCi/g) \\
\cline { 3 - 4 } & & No DU & Baseline Average \\
\hline Original & $/-/$ & $1.17 \mathrm{E}+07$ & $1.17 \mathrm{E}+07$ \\
\hline caustic slurry & 0 & 178 & 77.2 \\
\hline Aging 1 & 1 & 78.2 & 82.5 \\
\hline Aging 2 & 2 & 164 & 111 \\
\hline Aging 3 & 3 & 144 & 62.9 \\
\hline Aging 4 & 4 & 139 & 78.9 \\
\hline decant+wash & 8 & 63.5 & 33.4 \\
\hline MST 1 & 10 & 43 & 9.23 \\
\hline MST 2 & 11 & 41.8 & 14.8 \\
\hline
\end{tabular}

Table 6. Numerical Data for the Baseline and Experiment without Depleted Uranium.

Between the neutralization (caustic slurry) and Aging \#1 data points, a decrease in activity occurred in this experiment.

Since we know the total alpha activity of both the Am/Cm supernatant liquid and the Tank $51 \mathrm{H}$ surrogate, we can estimate the activity of the mixed composite. Table 7 lists 


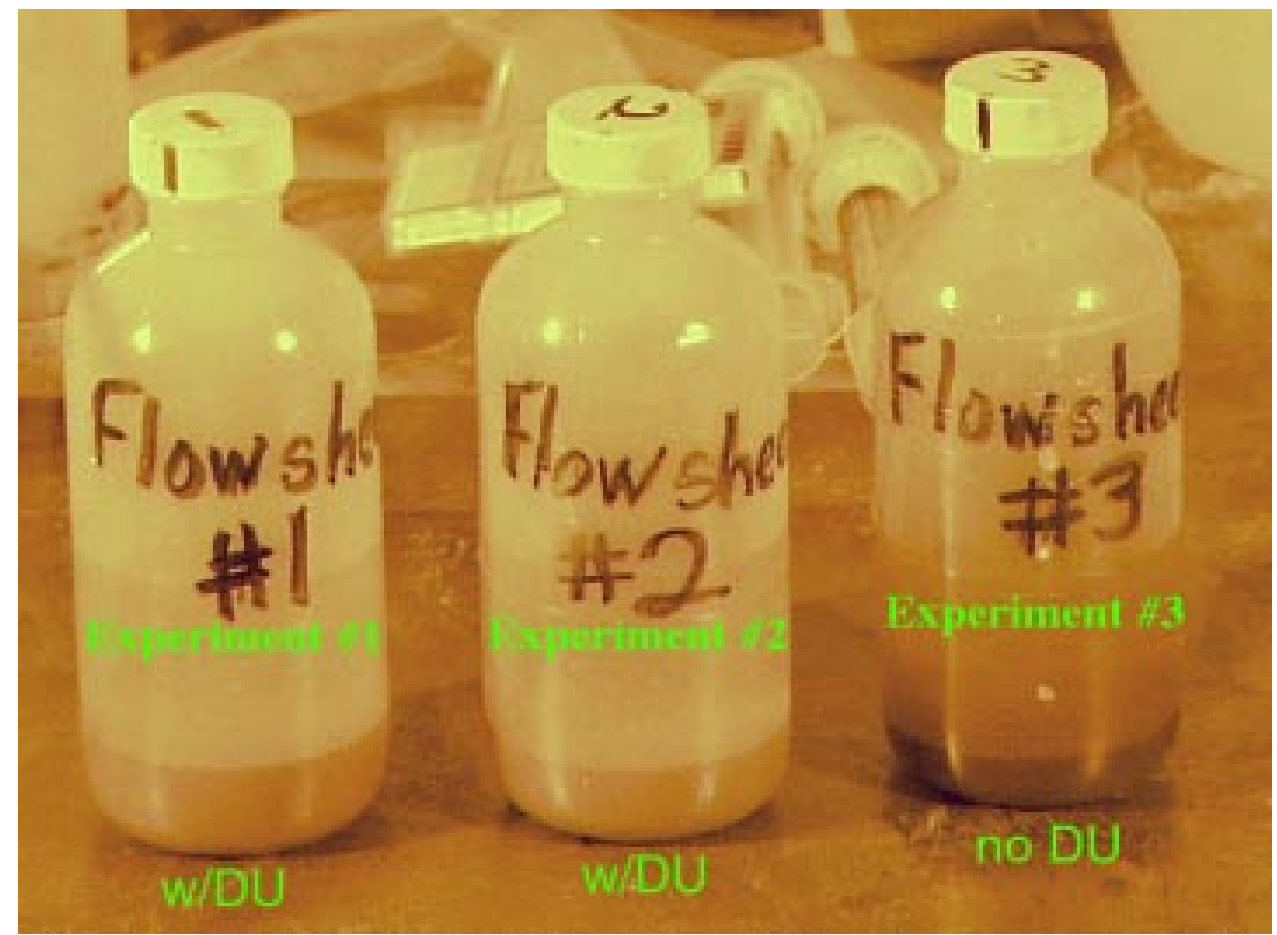

the total alpha activities of the neutralized Am/Cm slurries, as well as the activity of the Tank 51H surrogate (MTC \#1) and the estimated and measured activities of their

Figure 5. Caustic Added Slurries for the First Three Experiments.

respective composites (i.e., the "Aging 1" data points). The activity for the theoretical mix point far exceeds the measured activity, suggesting additional decontamination

\begin{tabular}{|l|c|}
\hline \multicolumn{1}{|c|}{ Supernatant Liquid } & Total Alpha Activity (nCi/g) \\
\hline Experiment \#3 (No DU) & 178 \\
\hline MTC \#1 & 753 \\
\hline No DU + MTC \#1 estimate & 375 \\
\hline No DU + MTC \#1 measured & 78.2 \\
\hline
\end{tabular}

Table 7. Estimated and Measured Activities of the Neutralized and Aged Slurries.

occurred after combining the two slurries. However, activities of the MTC \#1+Am/Cm slurries contain a high bias due to the cesium content. Hence, the magnitude of additional decontamination achieved, if any, proves difficult to assess.

The following Aging data points stayed approximately the same as the first aging sample, with no significant change in the total alpha activity over the four week period. Whatever 
WSRC-TR-2002-00029

dilution, leaching, or adsorption effects that may be occurring approximately cancel each other out.

After the aging step, the researchers decanted the supernatant liquid, and then washed the sludge three times with inhibited water. While we sampled and analyzed each of the decants and washes for total alpha activity, we present the data in this stage as a volume adjusted average. The original supernatant liquid from the aging process (i.e., the decant) underwent a $\sim 4$.8x dilution during the washing process. This dilution was calculated as the volume of the decant divided by the total supernatant liquid volume removed during the decants and washes. Table 8 shows the data for each of the decant and wash as compared to the baseline experiments. The overall decline compares the decant activity to the composite activity.

\begin{tabular}{|c|c|c|}
\hline \multirow{2}{*}{ Process } & \multicolumn{2}{|c|}{ Total Alpha Activity (nCi/g) } \\
\cline { 2 - 3 } & No DU & Baseline Average \\
\hline Decant & 174 & 83.8 \\
\hline Wash 1 & 37.5 & 24.7 \\
\hline Wash 2 & 56.5 & 30.5 \\
\hline Wash 3 & 29.0 & 14.2 \\
\hline $\begin{array}{c}\text { Decant/Wash } \\
\text { Composite }\end{array}$ & $63.5^{\partial}$ & 33.5 \\
\hline Overall Decline & $\mathbf{2 . 7 4 x}$ & $\mathbf{2 . 5 0 x}$ \\
\hline
\end{tabular}

Table 8. Total Alpha Activity of the Decant and Washes for the Experiment without Depleted Uranium.

This data indicates that of all effects from leaching, dilution, and aging, the decline in total alpha activity is slightly more than half the effective dilution introduced during this step. This would indicate that due to aging or precipitation, some actinides are being brought into solution, but to a lesser degree than dilution effects.

Finally, during the MST treatment step, the researchers took the decant and wash composite from the previous step and mixed it with a salt solution (see footnote, page 10) to generate a new composite. The effective dilution from adding the salt solution equaled 1.9. Researchers combined this new composite solution with $0.4 \mathrm{~g} / \mathrm{L}$ of MST and removed samples from the resulting slurry at 24 hours and 1 week. Results of the MST treatment on the new composite showed a decline in activity, putting the total alpha above the Saltstone limits. However, the decline occurs primarily due to the dilution effected in this step, rather than the effect of MST. Table 9 lists the total alpha activity of

\footnotetext{
${ }^{\partial}$ Due to a procedural error, the decant/wash composite activity for Experiment \#3 is estimated rather than precisely calculated.
} 
WSRC-TR-2002-00029

the decant/wash composite before and after the MST treatment for the baseline experiments.

\begin{tabular}{|c|c|c|}
\hline \multirow{2}{*}{ Process } & \multicolumn{2}{|c|}{ Total Alpha Activity (nCi/g) } \\
\cline { 2 - 3 } & No DU & Baseline Average \\
\hline $\begin{array}{c}\text { Decant/Wash } \\
\text { Composite }\end{array}$ & $63.5^{\partial}$ & 33.5 \\
\hline MST 1 & 43.0 & 9.23 \\
\hline MST 2 & 41.8 & 14.8 \\
\hline 24 hour Decline & $\mathbf{1 . 4 8 x}$ & $\mathbf{3 . 6 3 x}$ \\
\hline
\end{tabular}

MST 1 represents the data point taken 24 hours after the MST strike.

MST 2 provides the data point taken 1 week after the MST strike.

\section{Table 9. Total Alpha Activity Before and After MST Treatment in the Experiment without Depleted Uranium.}

The data indicates no significant benefit from the MST treatment, and the decline in total alpha activity approximately equals the dilution introduced. The lack of an effective DF from MST could be attributed to uranium interference with the other actinides.

After each of the previous steps (caustic addition, aging, decant/washing, and MST treatment), the remaining material was saved and sampled periodically. The data from these samples is referred to as the "long term" data. We examined this data for any significant long term negative trends. Figure 6 shows the graph of this data, as well as some of the previously reported data as comparisons. In the case of the neutralized

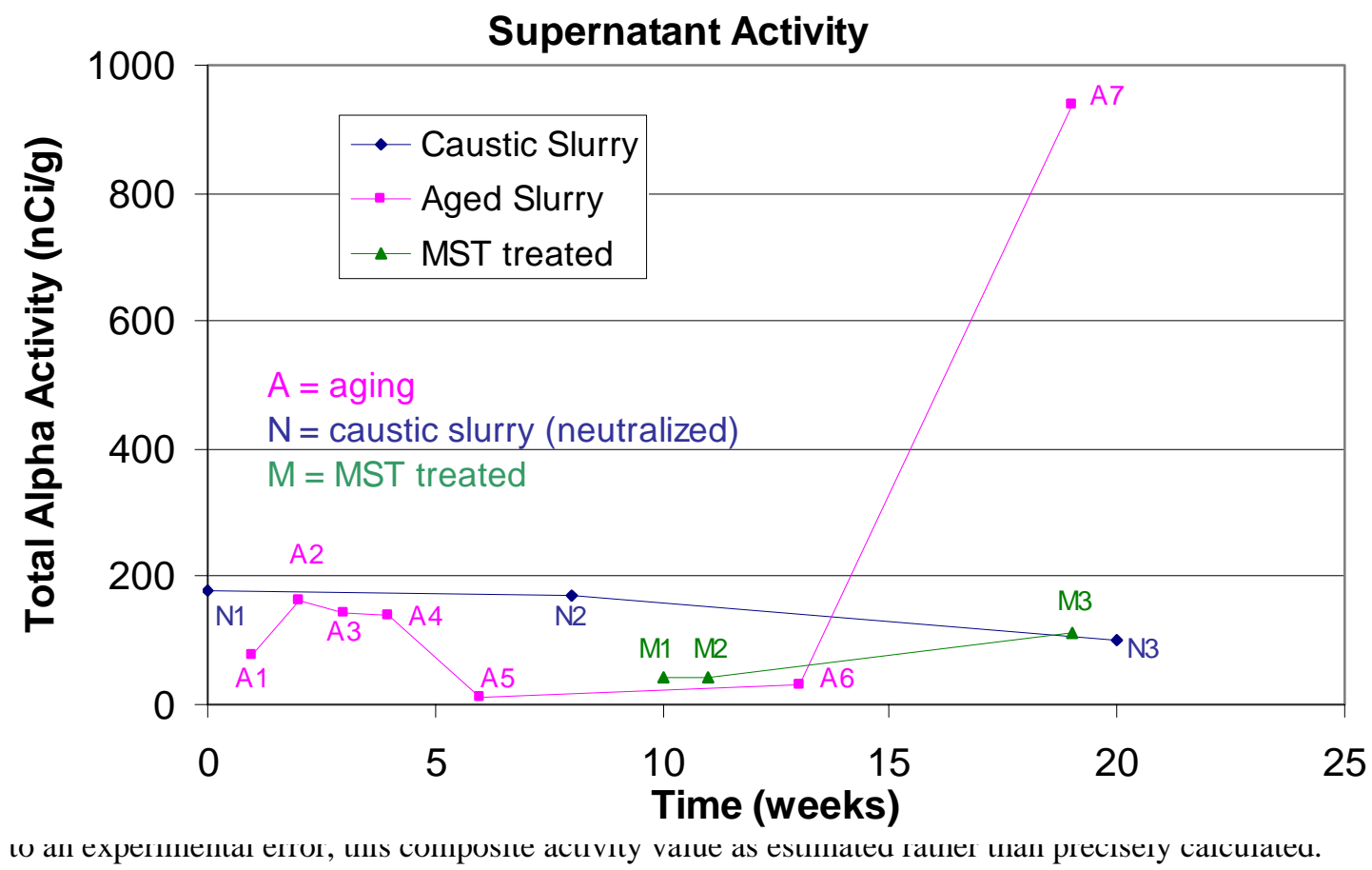


WSRC-TR-2002-00029

Figure 6. Long Term Data for the Experiment without Depleted Uranium.

(caustic) slurry, we see no significant variance. Over a period of 20 weeks, the activity of the caustic slurry seems to remain static. In the case of the aged slurry, we see a fairly large decline by five weeks (the fifth week data point is the first of the long term data points). The enormous increase in the last long term aging sample is suspect as a contaminated sample. In the case of the MST treatment data we see a slight increase in the activity, which we consider to be a not significant variance.

\title{
4.4 Permanganate Addition after Neutralization Process (Experiment \#4)
}

Experiment \#4 ("Permanganate") represented the first of the "mitigation" studies. The mitigation studies model potential process options to enhance the actinide removal efficiency prior to transfer of the slurry to the waste tanks. In this case, just after the addition of the caustic and tap water, personnel added a quantity of sodium permanganate, $\mathrm{NaMnO}_{4}$, and sodium formate, $\mathrm{NaHCO}_{2}$. The formate reduces the permanganate to form solids that might further adsorb the remaining soluble actinides. This simulates a manganese strike $\left(\mathrm{MnO}_{2}\right.$ can sorb actinides) that could occur in the canyon. This experiment used the following recipe.

\author{
$9.40 \mathrm{~mL}$ of depleted uranium solution $\left(350 \mathrm{~g} / \mathrm{L}\right.$ of $\left.{ }^{238} \mathrm{U}\right)$ \\ 13.0 mL of Tank 17.1 solution \\ $17.4 \mathrm{~mL}$ of $50 \mathrm{wt} \% \mathrm{NaOH}$ solution \\ $91.4 \mathrm{~mL}$ of process water \\ $6 \mathrm{~mL}$ of $0.24 \mathrm{M} \mathrm{NaMnO}_{4}$ solution \\ $10 \mathrm{~mL}$ of a $0.52 \mathrm{M} \mathrm{NaHCO}_{2}$ solution
}

The resulting tan caustic slurry settled within a few hours. Throughout the entire experimental sequence, we obtained eight data points. Figure 7 shows a graph comparing the baseline average to the Experiment \#4 data set while Table 10 shows the numerical data. We present the decant and wash data as a volume adjusted composite value and not as separate data points, simply for purposes of clarity. 
WSRC-TR-2002-00029

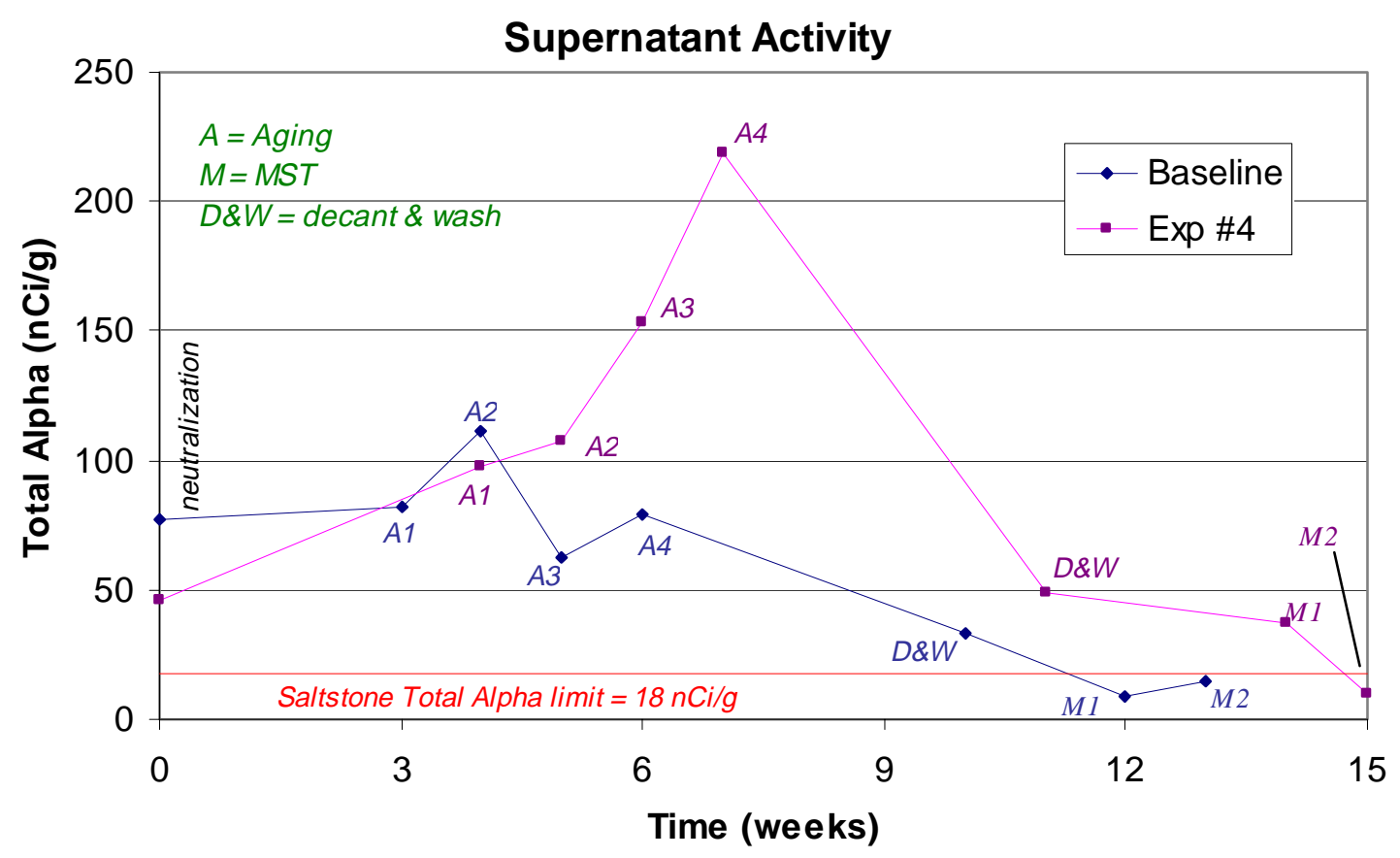

Figure 7. Total Alpha Activity Over Time for Baseline Average vs. Permanganate.

\begin{tabular}{|l|c|c|c|}
\hline \multicolumn{1}{|c|}{ Data Point } & Time (weeks) & Activity (nCi/g) & Activity (nCi/g) \\
\cline { 2 - 4 } & & Permanganate & Baseline Average \\
\hline Original & /-/ & $1.17 \mathrm{E}+07$ & $1.17 \mathrm{E}+07$ \\
\hline caustic slurry & 0 & 45.5 & 77.2 \\
\hline aging 1 & 1 & 97.5 & 82.5 \\
\hline aging 2 & 2 & 107 & 111 \\
\hline aging 3 & 3 & 153 & 62.9 \\
\hline aging 4 & 4 & 219 & 78.9 \\
\hline decant+wash & 8 & 49.1 & 33.4 \\
\hline MST 1 & 10 & 36.7 & 9.23 \\
\hline MST 2 & 11 & 10.1 & 14.8 \\
\hline
\end{tabular}

Table 10. Numerical Data for the Permanganate Experiment.

Between the neutralization (caustic slurry) and Aging \#1 data points, an increase in activity occurred in this experiment. 
Since we know the total alpha activity of both the Am/Cm supernatant liquid and the Tank $51 \mathrm{H}$ surrogate, we can estimate the activity of the mixed composite. Table 11 lists the total alpha activities of the neutralized Am/Cm slurries, as well as the activity of the Tank 51H surrogate (MTC \#1) and the estimated and measured activities of their respective composites (i.e., the "Aging 1" data points). The activity of the theoretical mix point far exceeds the measured value - although to a lesser degree than in the previous

\begin{tabular}{|l|c|}
\hline \multicolumn{1}{|c|}{ Supernatant Liquid } & Total Alpha Activity (nCi/g) \\
\hline Exp. \#4 (permanganate) & 45.5 \\
\hline MTC \#1 & 753 \\
\hline Exp \#4 + MTC \#1 estimate & 488 \\
\hline Exp \#4 + MTC \#1 measured & 97.5 \\
\hline
\end{tabular}

Table 11. Estimated and Measured Activities of the Neutralized and Aged Slurries.

demonstrations, suggesting additional removal of actinides occurred after combining the two slurries. However, activities of the MTC \#1 + Am/Cm slurries contain a high bias due to the cesium content. Hence, the magnitude of additional decontamination achieved, if any, proves difficult to assess.

Note that the Aging data shows an upward trend, but not alarmingly so. Since the upward trend continued over four samples, the behavior does not appear to result from analytical or operator error across all the experiments, but rather from the analytical uncertainty. We cannot also conceive of a mechanism by which addition of permanganate would bring more curium into solution. However, like the previous experiments, the activity declines greatly during the decant, washes, and MST treatment. Eventually, the total alpha activity falls just above Saltstone requirements.

After the aging step, the researchers decanted the supernatant liquid, and then washed the sludge three times with inhibited water. While we analyzed each of the decants and washes separately for total alpha activity, we present the data in this stage as a volume adjusted average. The original supernatant liquid from the aging process (i.e., the decant) underwent $\mathrm{a} \sim 4.2 \mathrm{x}$ dilution during the washing process. We calculate this dilution as the volume of the decant divided by the total supernatant liquid volume removed during the decants and washes. In this demonstration, we removed less decant than in the previous experiments. Table 12 shows the data for each of the decant and washes for the baseline experiments. The overall decline compares the decant activity to the composite activity.

The overall decline compares the decant activity to the composite activity. This data indicates that of all effects from leaching, dilution, and aging, the decline in total alpha activity equals less than half expected from the effective dilution introduced during this step. This finding indicates some actinides leaching into solution, but the dilution overwhelms the increase from leaching. 
WSRC-TR-2002-00029

\begin{tabular}{|c|c|c|}
\hline \multirow{2}{*}{ Process } & \multicolumn{2}{|c|}{ Total Alpha Activity $(\mathrm{nCi} / \mathrm{g})$} \\
\cline { 2 - 3 } & Permanganate & Baseline Average \\
\hline Decant & 113 & 83.8 \\
\hline Wash 1 & 50.0 & 24.7 \\
\hline Wash 2 & 39.3 & 30.5 \\
\hline Wash 3 & 16.4 & 14.2 \\
\hline $\begin{array}{c}\text { Decant/Wash } \\
\text { Composite }\end{array}$ & 49.1 & 33.5 \\
\hline Overall Decline & $\mathbf{2 . 3 0 x}$ & $\mathbf{2 . 8 3 x}$ \\
\hline
\end{tabular}

\section{Table 12. Total Alpha Activity of the Decant and Washes for the Permanganate Experiment.}

Finally, during the MST treatment step, the researchers took the decant and wash composite from the previous step and mixed it with a salt solution (see footnote, page 10) to generate a new composite. The effective dilution from adding the salt solution equaled 2.3. Researchers combined this new composite solution with $0.4 \mathrm{~g} / \mathrm{L}$ of MST and removed samples from the resulting slurry at 24 hours and 1 week. Results of the MST treatment on the new composite showed a decline in activity, putting the total alpha below the Saltstone limits. The decline exceeds that due to the dilution effected in this step. Table 13 lists the total alpha activity of the decant/wash composite before and

\begin{tabular}{|c|c|c|}
\hline \multirow{2}{*}{ Process } & \multicolumn{2}{|c|}{ Total Alpha Activity (nCi/g) } \\
\cline { 2 - 3 } & Permanganate & Baseline Average \\
\hline $\begin{array}{c}\text { Decant/Wash } \\
\text { Composite }\end{array}$ & 49.1 & 33.5 \\
\hline MST 1 & 36.7 & 9.23 \\
\hline MST 2 & 10.1 & 14.8 \\
\hline 24 hour Decline & $\mathbf{1 . 3 4 x}$ & $\mathbf{3 . 6 3 x}$ \\
\hline
\end{tabular}

MST 1 represents the data point taken 24 hours after the MST strike. MST 2 provides the data point taken 1 week after the MST strike.

\section{Table 13. Total Alpha Activity Before and After MST Treatment in the} Permanganate Experiment.

after the MST treatment for the baseline experiments. The data indicates some no effective benefit to the MST treatment. 
WSRC-TR-2002-00029

This experiment showed a continuous upward trend in activity from the neutralization through the aging steps. Like the previous experiments, the activity declines greatly during the decant, washes, and MST treatment. Eventually, the total alpha activity falls above Saltstone requirements (at 24 hours). The permanganate treatment seems to provide only a marginal improvement for the actinide removal efficiency during the initial treatment. However, the gain appears minimal considering the added complexity in terms of both equipment and operation - required to achieve the benefit.

After each of the previous steps (caustic addition, aging, decant/washing, and MST treatment), the remaining material was saved and sampled periodically. The data from these samples is referred to as the "long term" data. We examined this data to look for any significant long-term negative trends. Figure 8 shows the graph of the long-term data, with previously reported data used as comparisons. In the case of the caustic (neutralized) slurry, we see no real overall trend. Over 20 weeks of time, the caustic slurry shows no significant variance. In the case of the aged slurry, we see a fairly large decline by the fifth week (the fifth week point is the first of the long-term data), followed by a leveling out.

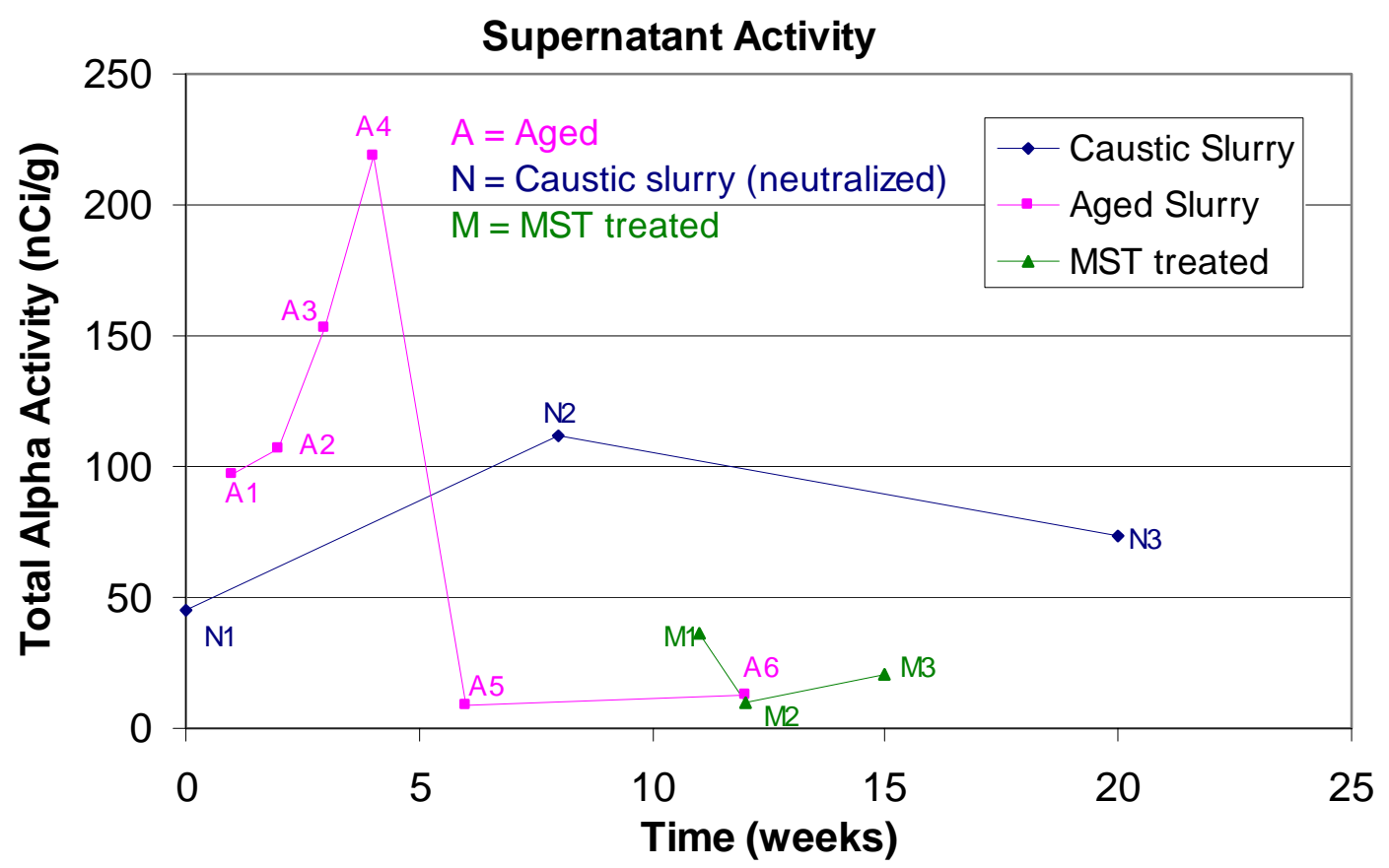

Figure 8. Long Term Data for the Permanganate Experiment.

In the case of the MST treatment data we see a slight overall decrease in the activity, which we consider to be not significant.

4.5 Baseline Process with in situ Monosodium Titanate Treatment (Experiment \#5) 
Experiment \#5 ("Extra MST experiment") followed the baseline treatment process but added treatment with monosodium titanate to sorb the remaining soluble actinides. This simulates a MST treatment that could occur in the F-Canyon vessel. This experiment used the following recipe.

9.40 $\mathrm{mL}$ of depleted uranium solution $\left(350 \mathrm{~g} / \mathrm{L}\right.$ of $\left.{ }^{238} \mathrm{U}\right)$

13.0 $\mathrm{mL}$ of Tank 17.1 solution

$17.4 \mathrm{~mL}$ of $50 \mathrm{wt} \% \mathrm{NaOH}$ solution

91.4 $\mathrm{mL}$ of process water

$\mathbf{0 . 5 4}$ g of 23 wt \% MST slurry

The resulting tan caustic slurry settled in the space of a few hours. Throughout the entire experimental sequence, we obtained eight data points. Figure 9 shows a graph comparing the baseline average to the Experiment \#5 data set while Table 14 shows the numerical data. We present the decant and wash data as a volume adjusted composite value and not as separate data points, simply for purposes of clarity.

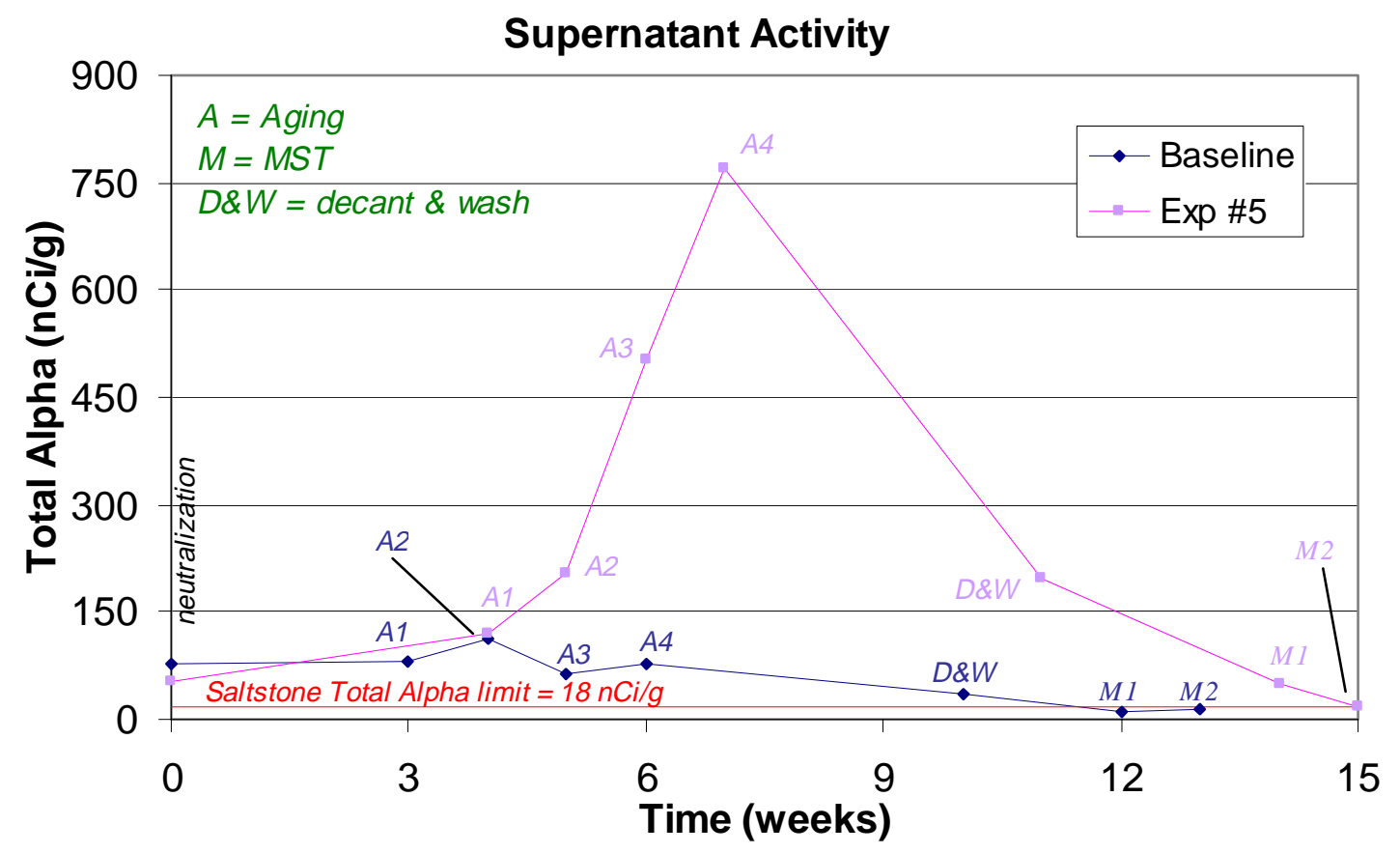

Figure 9. Total Alpha Activity Over Time for Extra MST Experiment.

\begin{tabular}{|l|c|c|c|}
\hline \multirow{2}{*}{ Data Point } & Time (weeks) & Activity (nCi/g) & Activity (nCi/g) \\
\cline { 3 - 4 } & & Extra MST & Baseline Average \\
\hline Original & /-/ & $1.17 \mathrm{E}+07$ & $1.17 \mathrm{E}+07$ \\
\hline caustic slurry & 0 & 52.4 & 77.2 \\
\hline aging 1 & 1 & 121 & 82.5 \\
\hline aging 2 & 2 & 203 & 111 \\
\hline aging 3 & 3 & 504 & 62.9 \\
\hline aging 4 & 4 & 770 & 78.9 \\
\hline
\end{tabular}


WSRC-TR-2002-00029

\begin{tabular}{|l|c|c|c|}
\hline decant+wash & 8 & 197 & 33.4 \\
\hline MST 1 & 10 & 49.1 & 9.23 \\
\hline MST 2 & 11 & 18.4 & 14.8 \\
\hline
\end{tabular}

Table 14. Numerical Data for the Extra MST Experiment.

Between the neutralization (caustic slurry) and Aging \#1 data points, an increase in activity occurred in this experiment. Since we know the total alpha activity of both the Am/Cm supernatant liquid and the Tank $51 \mathrm{H}$ surrogate, we can estimate the activity of the mixed composite. Table 15 lists the total alpha activities of the neutralized $\mathrm{Am} / \mathrm{Cm}$ slurries, as well as the activity of the Tank $51 \mathrm{H}$ surrogate (MTC \#1) and the estimated and measured activities of their respective composites (i.e., the "Aging 1" data points).

\begin{tabular}{|l|c|}
\hline \multicolumn{1}{|c|}{ Supernatant Liquid } & Total Alpha Activity (nCi/g) \\
\hline Exp. \#5 (Extra MST) & 52.4 \\
\hline MTC \#1 & 753 \\
\hline Exp \#5 + MTC \#1 estimate & 490 \\
\hline Exp \#5 + MTC \#1 measured & 121 \\
\hline
\end{tabular}

Table 15. Estimated and Measured Activities of the Neutralized and Aged Slurries.

The activity of the theoretical mix point far exceeds the measured value - although to a lesser degree than in the previous demonstrations, suggesting additional removal of actinides occurred after combining the two slurries. However, activities of the MTC \#1+ $\mathrm{Am} / \mathrm{Cm}$ slurries contain a high bias due to the cesium content. Hence, the magnitude of additional decontamination achieved, if any, proves difficult to assess.

The Aging data shows an upward trend, but not alarmingly so. In the case of this experiment, we think the activities of the third and fourth aging samples most likely result from contamination, as the activity exceeds the theoretical estimate. However, like the previous experiments, the activity declines greatly during the decant, washes, and MST treatment. Eventually, the total alpha activity falls just above Saltstone requirements.

After the aging step, the researchers decanted the supernatant liquid, and then washed the sludge three times with inhibited water. While we analyzed each of the decants and washes for total alpha activity, we present the data in this stage as a volume adjusted average. The original supernatant liquid from the aging process (i.e., the decant) underwent a $\sim 11 \mathrm{x}$ dilution during the washing process. We calculate this dilution as the volume of the decant divided by the total supernatant liquid volume removed during the decants and washes. The higher effective dilution in this experiment, as compared to the first three, shows the variable nature of settling in the slurry. In this case, we removed 
less decant than in the first three experiments. Table 16 shows the data for each of decant and wash as compared to the baseline experiments. The overall decline compares the decant activity to the composite activity. This data indicates that of all effects from leaching, dilution, and aging, the decline in total alpha activity equals less than half that expected from the effective dilution introduced during this step. This finding indicates some actinides leaching into solution, but the dilution overwhelms the increase from leaching.

Finally, during the (final) MST treatment, the researchers took the decant/wash composite from the previous step and mixed it with a salt solution (see footnote, page 10) to generate a new composite. The effective dilution from adding the salt solution equaled

\begin{tabular}{|c|c|c|}
\hline \multirow{2}{*}{ Process } & \multicolumn{2}{|c|}{ Total Alpha Activity (nCi/g) } \\
\cline { 2 - 3 } & Extra MST & Baseline Average \\
\hline Decant & 856 & 83.8 \\
\hline Wash 1 & 119 & 24.7 \\
\hline Wash 2 & 133 & 30.5 \\
\hline Wash 3 & 156 & 14.2 \\
\hline $\begin{array}{c}\text { Decant/Wash } \\
\text { Composite }\end{array}$ & 197 & 33.5 \\
\hline Overall Decline & $\mathbf{4 . 3 5 x}$ & $\mathbf{2 . 5 0 x}$ \\
\hline
\end{tabular}

Table 16. Total Alpha Activity of the Decant and Washes for the Extra MST Experiment.

2.3. Researchers combined this new composite solution with $0.4 \mathrm{~g} / \mathrm{L}$ of MST and removed samples from the resulting slurry at 24 hours and 1 week. Results of the MST treatment on the new composite showed a decline in activity, putting the total alpha above the Saltstone limits. Table 17 lists the total alpha activity of the decant/wash composite before and after the MST treatment as compared to the baseline experiments.

\begin{tabular}{|c|c|c|}
\hline \multirow{2}{*}{ Process } & \multicolumn{2}{|c|}{ Total Alpha Activity $(\mathrm{nCi} / \mathrm{g})$} \\
\cline { 2 - 3 } & Extra MST & Baseline Average \\
\hline $\begin{array}{c}\text { Decant/Wash } \\
\text { Composite }\end{array}$ & 197 & 33.5 \\
\hline MST 1 & 49.1 & 9.23 \\
\hline MST 2 & 18.4 & 14.8 \\
\hline Overall Decline & $\mathbf{4 . 0 1 x}$ & $\mathbf{3 . 6 3 x}$ \\
\hline
\end{tabular}

MST 1 represents the data point taken 24 hours after the MST strike. MST 2 provides the data point taken 1 week after the MST strike. 
WSRC-TR-2002-00029

Table 17. Total Alpha Activity Before and After MST Second Treatment in the Extra MST Experiment.

The data shows a net positive benefit from the (second, non-Canyon) MST treatment. The additional MST treatment within the Canyon seems to provide no improvement for the actinide removal efficiency than the baseline experiment.

After each of the previous steps (caustic addition, aging, decant/washing, and MST treatment), the remaining material was saved and sampled periodically. The data from these samples is referred to as the "long term" data. We used this data to look for any significant long-term negative trends. Figure 10 shows the graph of the long-term data,

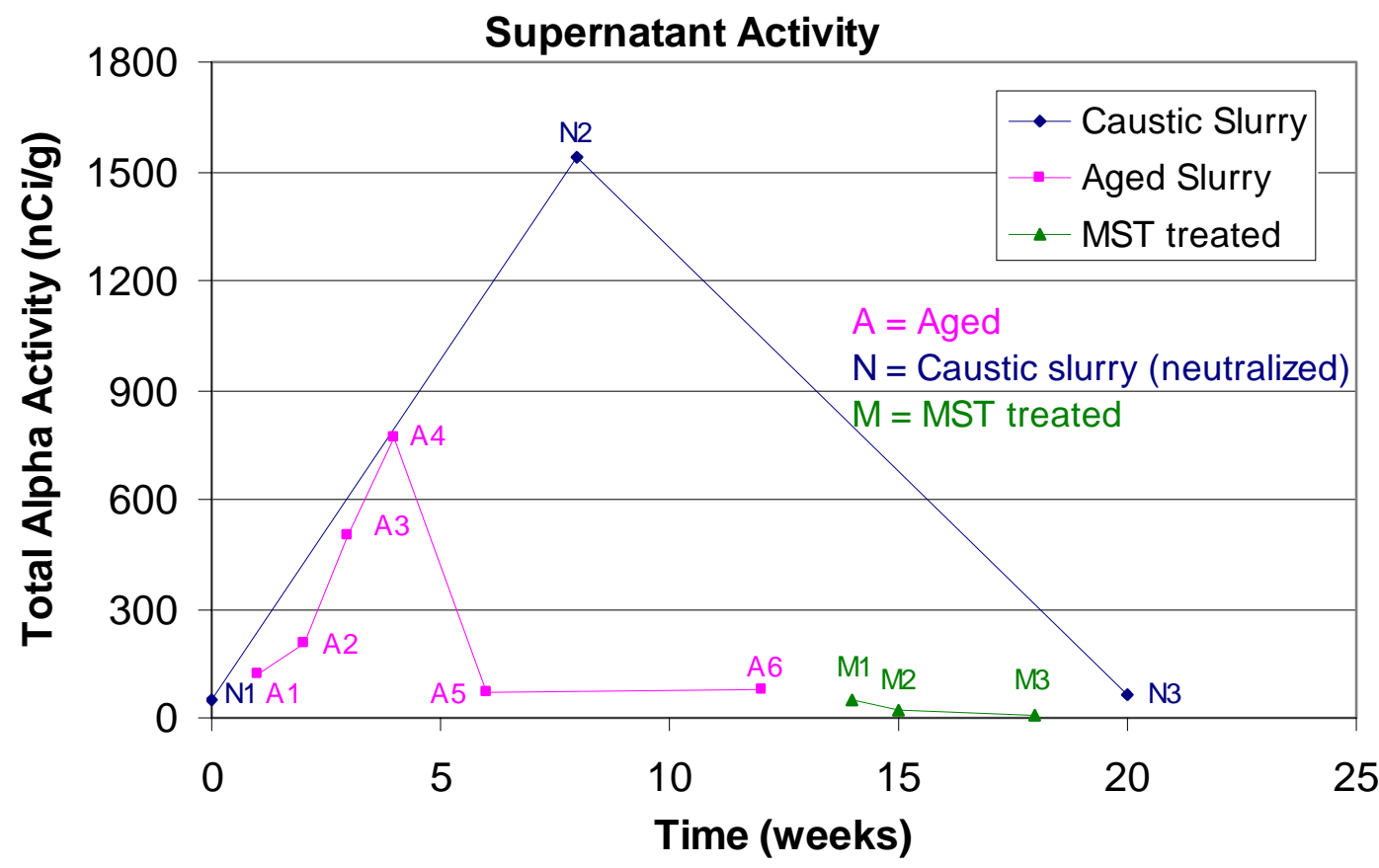

Figure 10. Long Term Data for Extra MST Experiment.

with some previously reported data used as comparisons. In the case of the caustic (neutralized) slurry, we see no overall significant changes over a period of 20 weeks. The large increase noted in the second data point is almost certainly due to contamination or error, and not a temporary 20 fold increase over 8 weeks. In the case of the aged slurry, we see a fairly large decline by five weeks (where the fifth week data point is the first of the long-term data), followed by a leveling off. In the case of the MST treatment data we see a slight decrease in the activity, which we consider to be not a significant change.

\subsection{Treatment using Ferric Nitrate (Experiment \#6)}

Experiment \#6 ("Iron experiment") replaced the depleted uranium from the baseline process with ferric nitrate, $\mathrm{Fe}\left(\mathrm{NO}_{3}\right)_{3}$, on an uranium-for-iron equal mass basis. This experiment used the following recipe. 
WSRC-TR-2002-00029

$9.4 \mathrm{~mL}$ of a ferric nitrate slurry ( $23.7 \mathrm{~g}$ of ferric nitrate in $9.4 \mathrm{~mL})$

13.0 $\mathrm{mL}$ of Tank 17.1 solution

$17.4 \mathrm{~mL}$ of $50 \mathrm{wt} \% \mathrm{NaOH}$ solution

$91.4 \mathrm{~mL}$ of process water

We added enough solid $\mathrm{NaOH}$ to account for the fact that the iron will bind three hydroxide molecules vs. the uranium binding two hydroxides. Failure to account for this would decrease the free hydroxide. The resulting brown caustic slurry settled within a few hours. Throughout the entire experimental sequence, we obtained eight data points. Figure 11 shows a graph comparing the baseline average to the Experiment \#6 data set while Table 18 shows the numerical data. We present the decant and wash data as a volume adjusted composite value and not as separate data points.

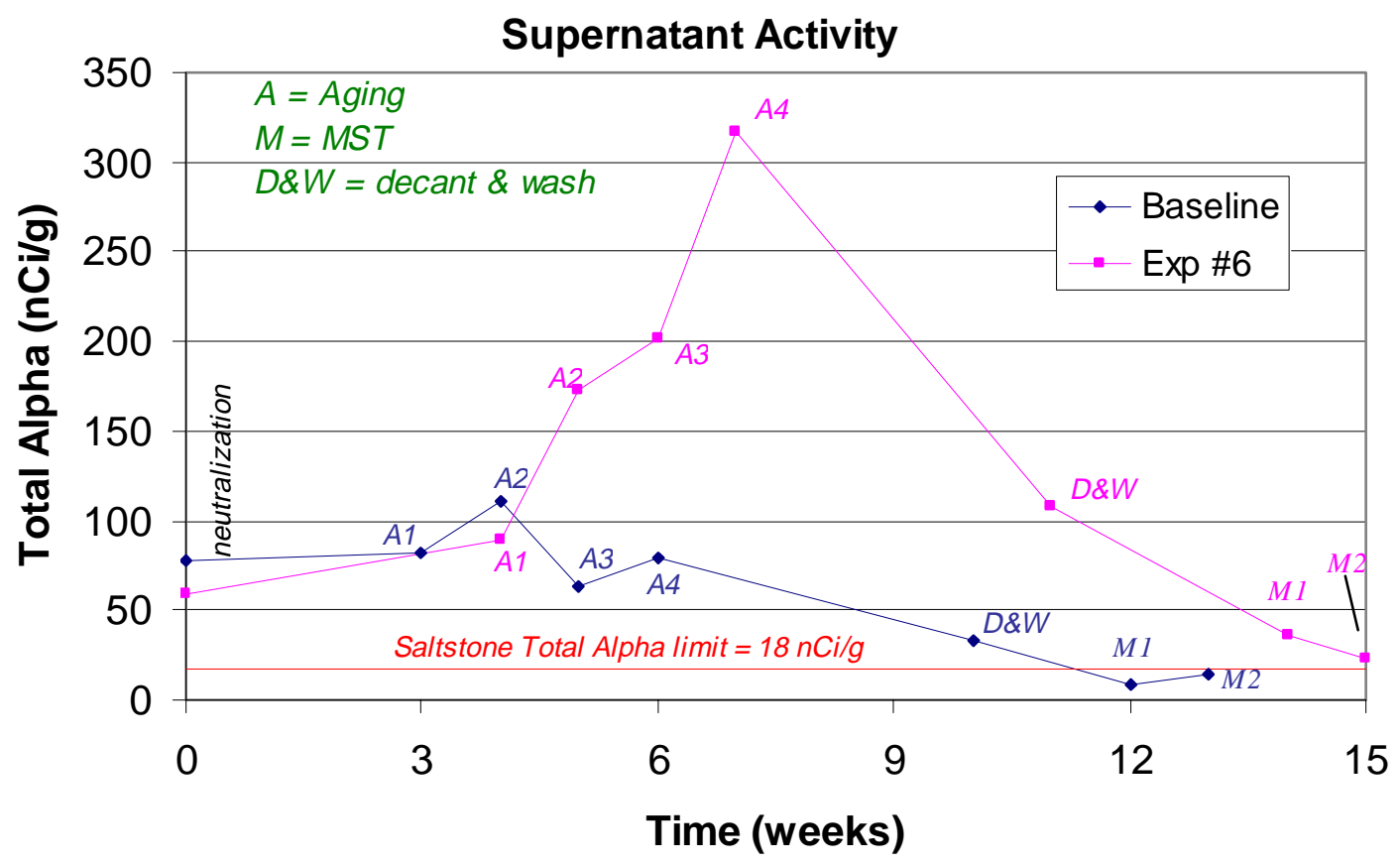

Figure 11. Total Alpha Activity Over Time for the Iron Experiment.

\begin{tabular}{|l|c|c|c|}
\hline \multicolumn{1}{|c|}{ Data Point } & Time (weeks) & Activity (nCi/g) & Activity (nCi/g) \\
\cline { 3 - 4 } & & Experiment \#6 & Baseline Average \\
\hline Original & $/-/$ & $1.17 \mathrm{E}+07$ & $1.17 \mathrm{E}+07$ \\
\hline caustic slurry & 0 & 59.4 & 77.2 \\
\hline aging 1 & 1 & 89.7 & 82.5 \\
\hline aging 2 & 2 & 173 & 111 \\
\hline aging 3 & 3 & 201 & 62.9 \\
\hline
\end{tabular}


WSRC-TR-2002-00029

\begin{tabular}{|l|c|c|c|}
\hline aging 4 & 4 & 317 & 78.9 \\
\hline decant+wash & 8 & 108 & 33.4 \\
\hline MST 1 & 10 & 36.6 & 9.23 \\
\hline MST 2 & 11 & 22.5 & 14.8 \\
\hline
\end{tabular}

Table 18. Numerical Data for the Iron Experiment.

Between the neutralization (caustic slurry) and Aging \#1 data points, an increase in activity occurred in this experiment. Since we know the total alpha activity of both the $\mathrm{Am} / \mathrm{Cm}$ supernatant liquid and the Tank $51 \mathrm{H}$ surrogate, we can estimate the activity of the mixed composite. Table 19 lists the total alpha activities of the neutralized Am/Cm slurries, as well as the activity of the Tank $51 \mathrm{H}$ surrogate (MTC \#1) and the estimated and measured activities of their respective composites

\begin{tabular}{|l|c|}
\hline \multicolumn{1}{|c|}{ Supernatant Liquid } & Total Alpha Activity (nCi/g) \\
\hline Experiment \#6 (Iron) & 59.4 \\
\hline MTC \#1 & 753 \\
\hline Exp \#6 + MTC \#1 estimate & 493 \\
\hline Exp \#6 + MTC \#1 measured & 121 \\
\hline
\end{tabular}

Table 19. Estimated and Measured Activities of the Neutralized and Aged Slurries.

(i.e., the "Aging 1" data points). The activity for the theoretical mix point far exceeds the measured activity, suggesting additional decontamination occurred after combining the two slurries. However, activities of the MTC \#1+Am/Cm slurries contain a high bias due to the cesium content. Hence, the magnitude of additional decontamination achieved, if any, proves difficult to assess.

The Aging data shows an upward trend, but not alarmingly so. Since the upward trend continued over four samples, the behavior does not appear to result from analytical or operator error across all the experiments, but rather from the analytical uncertainty. We cannot conceive of a mechanism by which substituting iron for uranium would bring more curium into solution. However, like the previous experiments, the activity declines greatly during the decant, washes, and MST treatment. Eventually, the total alpha activity falls just above Saltstone requirements.

After the aging step, the researchers decanted the supernatant liquid, and then washed the sludge three times with inhibited water. While we analyzed each of the decants and washes for total alpha activity, we present the data in this stage as a volume adjusted average. The original supernatant liquid from the aging process (i.e., the decant) underwent a $\sim 5.1 \mathrm{x}$ dilution during the washing process. We calculate this dilution as the volume of the decant divided by the total supernatant liquid volume removed during the decants and washes. Table 20 shows the data for each decant and wash as compared to 
the baseline experiments. The overall decline compares the decant activity to the composite activity. This data indicates that of all effects from leaching, dilution, and aging, the decline in total alpha activity equals slightly more than half that expected from the effective dilution introduced during this step. This finding indicates some actinides leaching into solution, but the dilution overwhelms the increase from leaching.

\begin{tabular}{|c|c|c|}
\hline \multirow{2}{*}{ Process } & \multicolumn{2}{|c|}{ Total Alpha Activity (nCi/g) } \\
\cline { 2 - 3 } & Iron & Baseline Average \\
\hline Decant & 328 & 83.8 \\
\hline Wash 1 & 49.1 & 24.7 \\
\hline Wash 2 & 133 & 30.5 \\
\hline Wash 3 & 41.8 & 14.2 \\
\hline $\begin{array}{c}\text { Decant/Wash } \\
\text { Composite }\end{array}$ & 108 & 33.5 \\
\hline Overall Decline & $\mathbf{3 . 0 4 x}$ & $\mathbf{2 . 5 0 x}$ \\
\hline
\end{tabular}

Table 20. Total Alpha Activity of the Decant and Washes for the Iron Experiment.

Finally, during the MST treatment, the researchers took the decant and wash composite from the previous step and mixed it with a salt solution (see footnote, page 10) to generate a new composite. The effective dilution from adding the salt solution equaled 2.1. Researchers combined this new composite solution with $0.4 \mathrm{~g} / \mathrm{L}$ of MST and removed samples from the resulting slurry at 24 hours and 1 week. Results of the MST treatment on the new composite showed a decline in activity, putting the total alpha above the Saltstone limits. Table 21 lists the total alpha activity of the decant/wash composite before and after the MST treatment as compared to the baseline experiments.

\begin{tabular}{|c|c|c|}
\hline \multirow{2}{*}{ Process } & \multicolumn{2}{|c|}{ Total Alpha Activity (nCi/g) } \\
\cline { 2 - 3 } & Iron & Baseline Average \\
\hline $\begin{array}{c}\text { Decant/Wash } \\
\text { Composite }\end{array}$ & 108 & 33.5 \\
\hline MST 1 & 36.6 & 9.23 \\
\hline MST 2 & 22.5 & 14.8 \\
\hline 24 hour Decline & $\mathbf{2 . 9 5 x}$ & $\mathbf{3 . 6 3 x}$ \\
\hline
\end{tabular}

MST 1 represents the data point taken 24 hours after the MST strike. MST 2 provides the data point taken 1 week after the MST strike.

Table 21. Total Alpha Activity Before and After MST Treatment in the Iron Experiment. 
WSRC-TR-2002-00029

The data indicates some effective benefit to the MST treatment.

After each of the previous steps (caustic addition, aging, decant/washing, and MST treatment), the remaining material was saved and sampled periodically. The data from these samples is referred to as the "long term" data. We used this data to look for any significant long-term negative trends. Figure 12 shows the graph of the long-term data, with some previously reported data points used as comparisons. In the case of the caustic (neutralized) slurry, we see no overall significant variance. Over a period of 20 weeks, the caustic slurry seems to remain relatively static. In the case of the aged slurry, we see a fairly large decline by the fifth week (of which the fifth week is the first of the long-term data), followed by a leveling off. In the case of the MST treatment data we

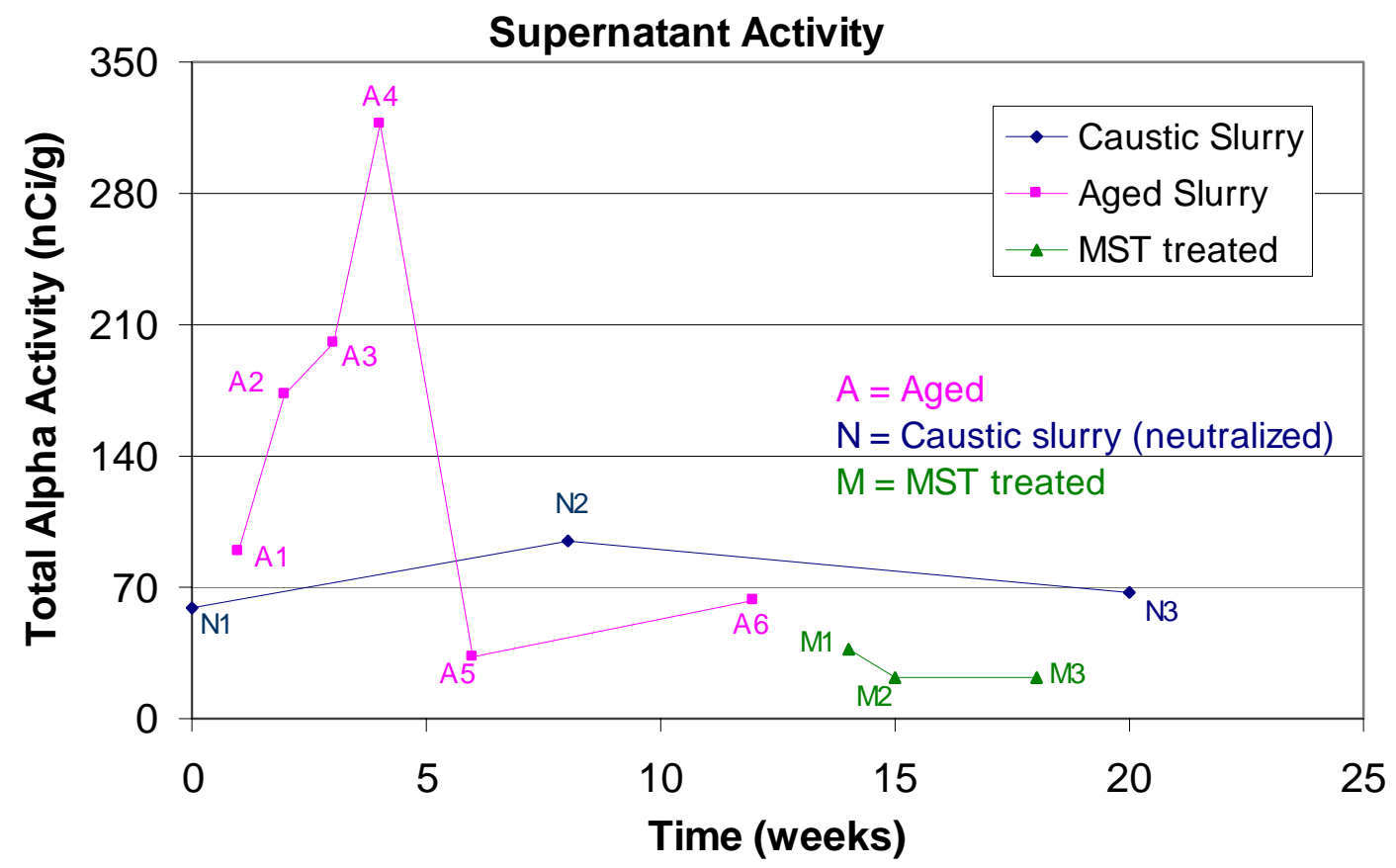

Figure 12. Long Term Data for the Iron Experiment.

see a slight decrease in the activity, which again we consider to be not significant.

\subsection{Baseline Process with Enhanced Nitrate (Experiment \#8)}

For Experiment \#8 ("Extra Nitrate experiment") we used a recipe for treatment with added nitrate derived from guidance provided by Loftin. ${ }^{15}$ Addition of nitrate decreases the amount of hydrogen that forms during radiolysis of the solution. The recipe follows.

$\mathbf{2 . 6 8} \mathrm{mL}$ of depleted uranium solution $\left(350 \mathrm{~g} / \mathrm{L}\right.$ of $\left.{ }^{238} \mathrm{U}\right)$

4.0 $\mathrm{mL}$ of Tank 17.1 solution

$14.3 \mathrm{~mL}$ of 40 wt $\% \mathrm{NaNO}_{3}$ solution

$4.8 \mathrm{~mL}$ of 50 wt $\% \mathrm{NaOH}$ solution

$14.3 \mathrm{~mL}$ of process water 
WSRC-TR-2002-00029

The resulting tan caustic slurry settled in a few hours. Throughout the entire experimental sequence, we obtained eight data points. Figure 13 shows a graph comparing the baseline average to the Experiment \#6 data set while Table 22 shows the numerical data. We present the decant and wash data as a volume adjusted composite value and not as separate data points.

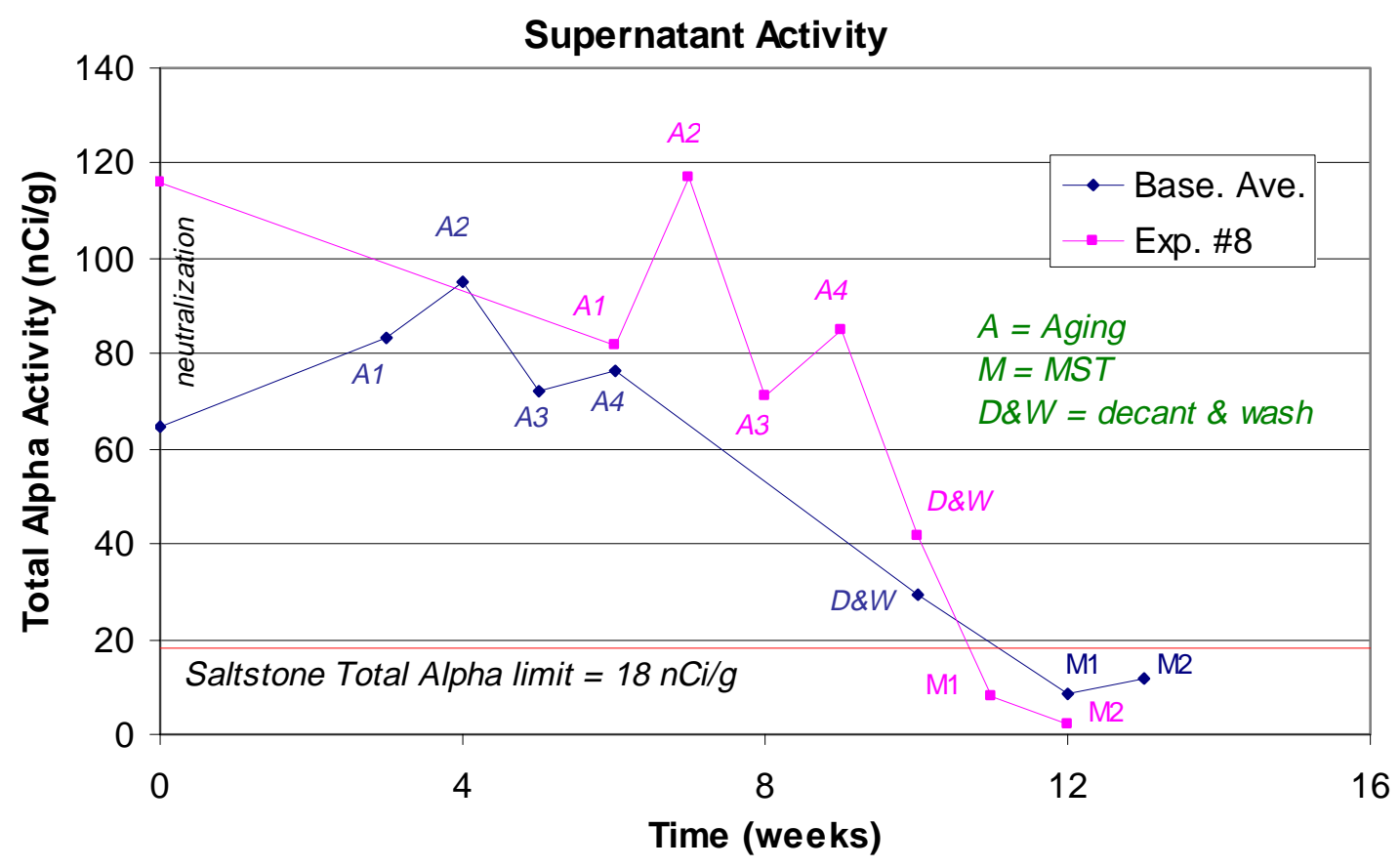

Figure 13. Total Alpha Activity Over Time for Baseline vs the Extra Nitrate Experiment.

\begin{tabular}{|l|c|c|c|}
\hline \multirow{2}{*}{ Data Point } & Time (weeks) & Activity (nCi/g) & Activity (nCi/g) \\
\cline { 2 - 4 } & & Extra Nitrate & Baseline Average \\
\hline Original & /-/ & $1.17 \mathrm{E}+07$ & $1.17 \mathrm{E}+07$ \\
\hline caustic slurry & 0 & 116 & 77.2 \\
\hline aging 1 & 1 & 81.5 & 82.5 \\
\hline aging 2 & 2 & 117 & 111 \\
\hline aging 3 & 3 & 71.3 & 62.9 \\
\hline aging 4 & 4 & 85.2 & 78.9 \\
\hline decant+wash & 8 & 41.9 & 33.4 \\
\hline MST 1 & 10 & 8.19 & 9.23 \\
\hline MST 2 & 11 & 2.03 & 14.8 \\
\hline
\end{tabular}

Table 22. Numerical Data for the Extra Nitrate Experiment. 
Between the neutralization (caustic slurry) and aging \#1 data points, a decrease in activity occurred in this experiment. Since we know the total alpha activity of both the Am/Cm supernatant liquid and the Tank $51 \mathrm{H}$ surrogate, we can estimate the activity of the mixed composite. Table 23 lists the total alpha activities of the neutralized Am/Cm slurries, as well as the activity of the Tank $51 \mathrm{H}$ surrogate (MTC \#2) and the estimated and measured activities of their respective composites (i.e., the "Aging 1" data points). The activity of the theoretical mixpoint far exceeds the measured activity (although to a lesser degree

\begin{tabular}{|l|c|}
\hline \multicolumn{1}{|c|}{ Supernatant Liquid } & Total Alpha Activity (nCi/g) \\
\hline Exp. \#8 (Extra Nitrate) & 116 \\
\hline MTC \#2 & 218 \\
\hline Exp \#8 + MTC \#2 estimate & 181 \\
\hline Exp \#8 + MTC \#2 measured & 81.5 \\
\hline
\end{tabular}

Table 23. Estimated and Measured Activities of the Neutralized and Aged Slurries.

than the most of the previous experiments). However, estimates of the MTC \#2+ $\mathrm{Am} / \mathrm{Cm}$ slurries are not necessarily meaningful due to the fact that both the MTC \#2 and $\mathrm{Am} / \mathrm{Cm}$ activities are upper bounds. This difference illustrates that there is a degree of variability in the upper bounds dependent on the sample.

The Aging data stays approximately the same as the first aging sample and there appears to be no large net change in the total alpha activity over the four week period. Whatever dilution, leaching, or adsorption effects that are occurring approximately cancel each other.

After the aging step, the researchers decanted the supernatant liquid, and then washed the sludge three times with inhibited water. While we analyzed each of the decants and washes for total alpha activity, we present the data in this stage as a volume adjusted average. The original supernatant liquid from the aging process (i.e., the decant) underwent a $\sim 2.6 \mathrm{x}$ dilution during the washing process. This dilution was calculated as the volume of the decant divided by the total supernatant liquid volume removed during the decants and washes. Table 24 shows the data for each of the decant and washes for the baseline experiments. The overall decline compares the decant activity to the

\begin{tabular}{|c|c|c|}
\hline \multirow{2}{*}{ Process } & \multicolumn{2}{|c|}{ Total Alpha Activity (nCi/g) } \\
\cline { 2 - 3 } & Extra Nitrate & Baseline Average \\
\hline Decant & 86.1 & 83.8 \\
\hline Wash 1 & 22.5 & 24.7 \\
\hline Wash 2 & 15.3 & 30.5 \\
\hline Wash 3 & 9.5 & 14.2 \\
\hline
\end{tabular}


WSRC-TR-2002-00029

\begin{tabular}{|c|c|c|}
\hline $\begin{array}{c}\text { Decant/Wash } \\
\text { Composite }\end{array}$ & 41.9 & 33.5 \\
\hline Overall Decline & $\mathbf{2 . 0 5}$ & $\mathbf{2 . 5 0 x}$ \\
\hline
\end{tabular}

\section{Table 24. Total Alpha Activity of the Decant and Washes for the Extra Nitrate Experiment.}

composite activity. This data indicates that of all effects from leaching, dilution, and aging, the decline in total alpha activity is approximately that of the effective dilution introduced during this step. This would indicate that due to aging or leaching, some actinides are being brought into solution, but the effect is less than introduced by dilution.

Finally, during the MST treatment step, the researchers took the decant and wash composite from the previous step and mixed it with a salt solution (see footnote, page 10) to generate a new composite. The effective dilution from adding the salt solution was 2.1. Researchers struck this new composite solution with $0.4 \mathrm{~g} / \mathrm{L}$ of MST and removed samples from the resulting slurry at 24 hours and 1 week. Results of the MST treatment on the new composite showed a decline in activity, putting the total alpha below the Saltstone limits. However, the decline occurs primarily due to the dilution effected in this step, rather than the effect of MST. Table 25 lists the total alpha activity of the decant and wash composite before and after the MST treatment for the baseline experiments. The data indicates that there could be some effective benefit to the MST treatment.

\begin{tabular}{|c|c|c|}
\hline \multirow{2}{*}{ Process } & \multicolumn{2}{|c|}{ Total Alpha Activity (nCi/g) } \\
\cline { 2 - 3 } & Extra Nitrate & Baseline Average \\
\hline $\begin{array}{c}\text { Decant/Wash } \\
\text { Composite }\end{array}$ & 41.9 & 33.5 \\
\hline MST 1 & 8.19 & 9.23 \\
\hline MST 2 & $2.03(\mathrm{DL})$ & 14.8 \\
\hline Overall Decline & $\mathbf{5 . 1 2 x}$ & $\mathbf{3 . 6 3 x}$ \\
\hline
\end{tabular}

MST 1 represents the data point taken 24 hours after the MST strike. MST 2 provides the data point taken 1 week after the MST strike.

\section{Table 25. Total Alpha Activity Before and After MST Treatment in the Extra} Nitrate Experiment.

\subsection{Leaching during Transfer (Experiment \#7)}

Experiment \#7 ("Leaching experiment") examined the leaching of a portion of neutralized slurry (after the acidic solution had caustic added, but before the addition of Tank $51 \mathrm{H}$ surrogate was added) following a five-fold dilution with inhibited water. We performed the dilution several weeks after the neutralization to simulate the hold time for 
the slurry in F-Canyon. After mixing, we allowed the resulting slurry to sit undisturbed except for taking samples. Figure 14 shows the total alpha activity during the leaching experiment, while Table 26 lists the numerical data.

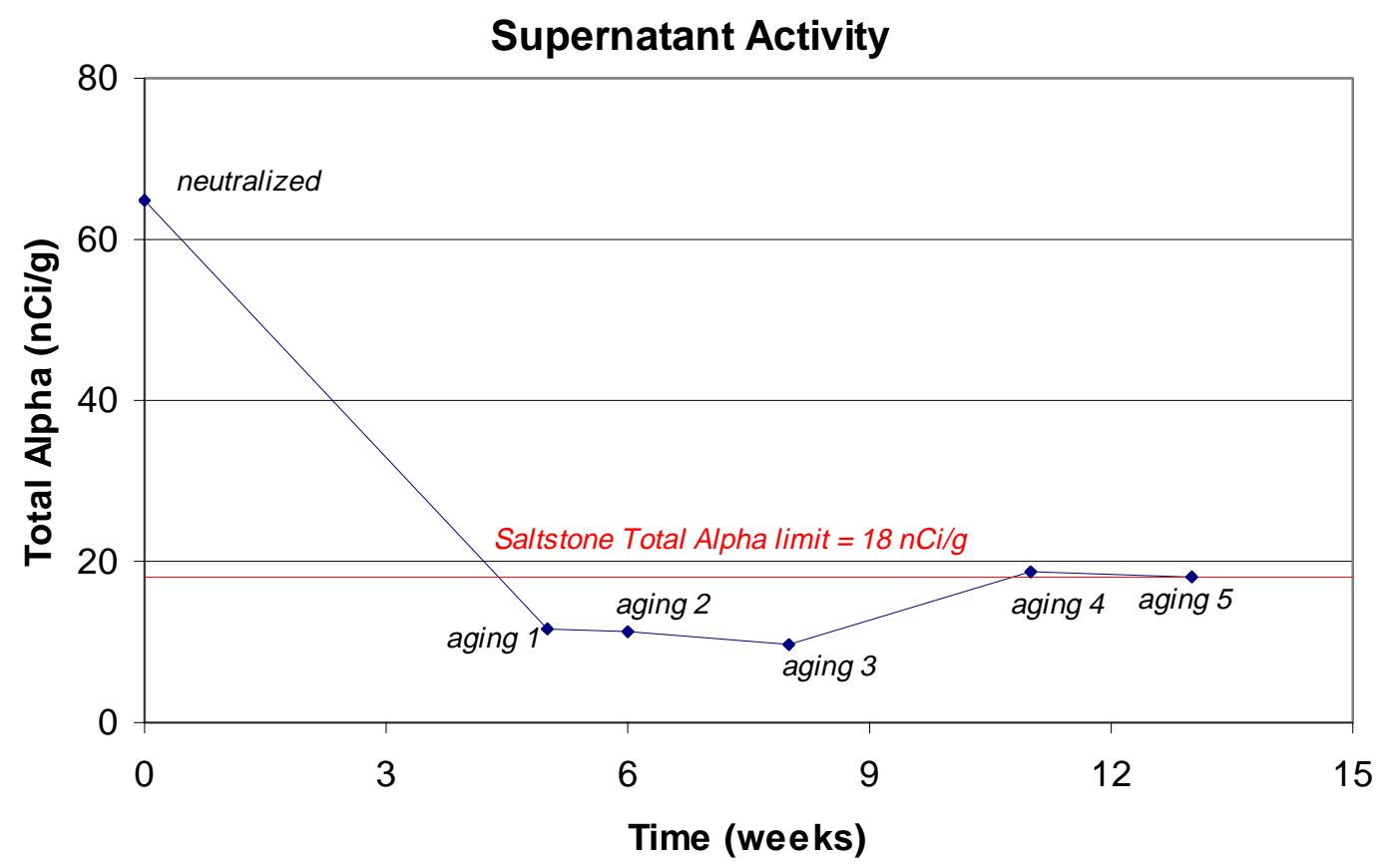

Figure 14. Total Alpha Activity Over Time for the Leaching Experiment.

\begin{tabular}{|l|c|c|}
\hline \multicolumn{1}{|c|}{ Data Point } & Time (weeks) & Activity (nCi/g) \\
\hline Caustic slurry & 0 & 64.7 \\
\hline Aging 1 & 5 & 11.5 \\
\hline Aging 2 & 6 & 11.3 \\
\hline Aging 3 & 8 & 9.6 \\
\hline Aging 4 & 11 & 18.6 \\
\hline Aging 5 & 13 & 18.2 \\
\hline $\begin{array}{l}\text { Est. diluted } \\
\text { activity }\end{array}$ & /-/ & 10.8 \\
\hline
\end{tabular}

Table 26. Numerical Data for Leaching During Transfer.

The original slurry had a supernatant liquid activity of $64.7 \mathrm{nCi} / \mathrm{g}$. After adding a $5 \mathrm{x}$ amount of inhibited water, the supernatant liquid activity dropped to almost exactly $1 / 6$ of 
the original value (11.5), as one would expect (i.e., estimated dilution gives 10.8). From then on, the total alpha activity remained fairly static, either under the Saltstone limits, or very slightly above them. This data indicates that a neutralized Am/Cm slurry undergoes no appreciable leaching, at least on the time scale of this experiment.

\subsection{Rheology Measurements}

Both Canyon and HLW personnel had concerns about high-nitrate slurries being too viscous. The Immobilization Technology Section was asked to characterize four basic slurries for the Americium-Curium (Am/Cm) flowsheet.

Three Am/Cm simulant slurries were prepared at three nitrate levels, all containing depleted uranium. The fourth slurry was an Am/Cm slurry that contained manganese as a substitute for depleted uranium.

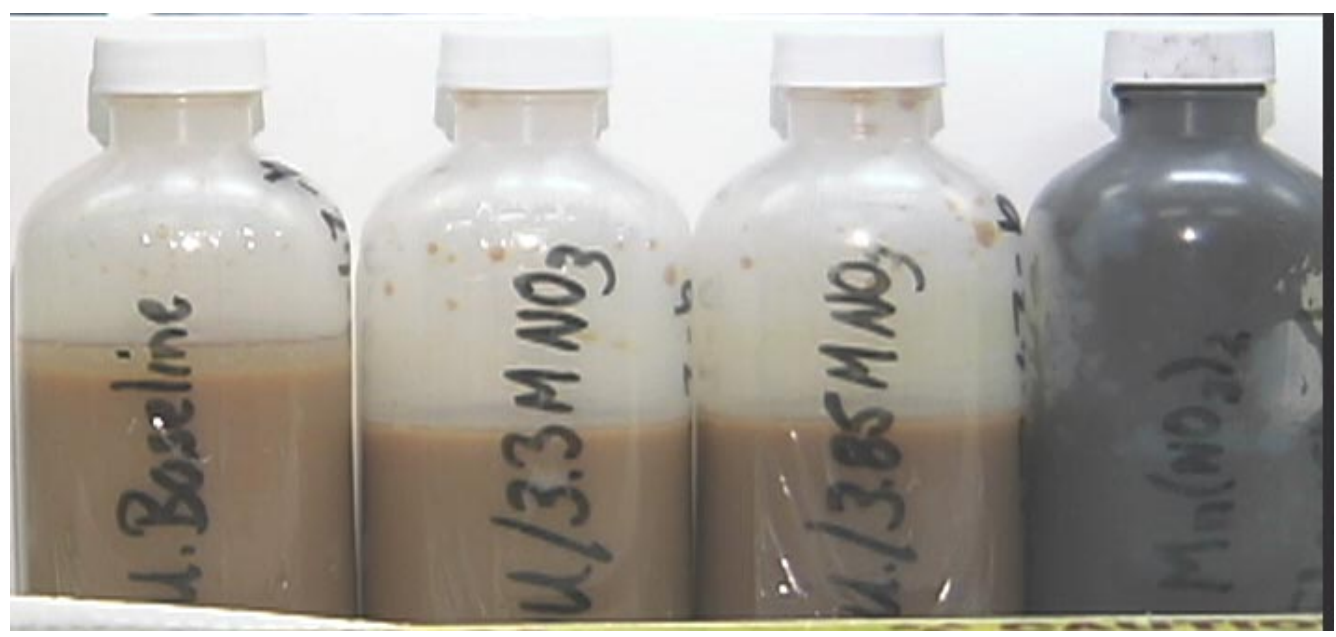

Figure 15. The Four Simulant Slurries; Baseline, 3.3 M Nitrate, 3.85 M Nitrate, Manganese Studies.

Rheological testing occurred in radioactive and nonradioactive lab hoods. The samples containing depleted uranium were each tested under identical testing conditions. The sample containing manganese was tested multiple times in an attempt to understand its rheological behavior. The rheological data was fit to the Bingham Plastic fluid model. The table below summarizes the results.

\begin{tabular}{|l|c|c|c|c|}
\hline Sample & Yield Stress, dynes $/ \mathrm{cm}^{2}$ & Consistency, $\mathrm{cP}$ & $\mathrm{R}^{2}$ & Density, g/mL \\
\hline Baseline Slurry $\#$ & 0.90 & 1.81 & 0.9936 & 1.12 \\
\hline
\end{tabular}


WSRC-TR-2002-00029

\begin{tabular}{|l|c|c|c|c|}
\hline 3.3 M nitrate & 4.15 & 3.38 & 0.9939 & 1.21 \\
\hline 3.85 M nitrate & 5.27 & 3.90 & 0.9945 & 1.23 \\
\hline Manganese \& & 67.9 & 4.81 & 0.9796 & 1.27 \\
\hline
\end{tabular}

Table 27. Summary of Bingham Plastic Fluid Parameters

With the DU containing slurries, as the nitrate content increased, so did the viscosity and density. With the manganese test, the slurry was far more viscous than in the DU cases.

For the purposes of showing relative flow characteristics, SRTC conducted an additional test, using a condenser column with a spiral cooling coil (Figure 16).

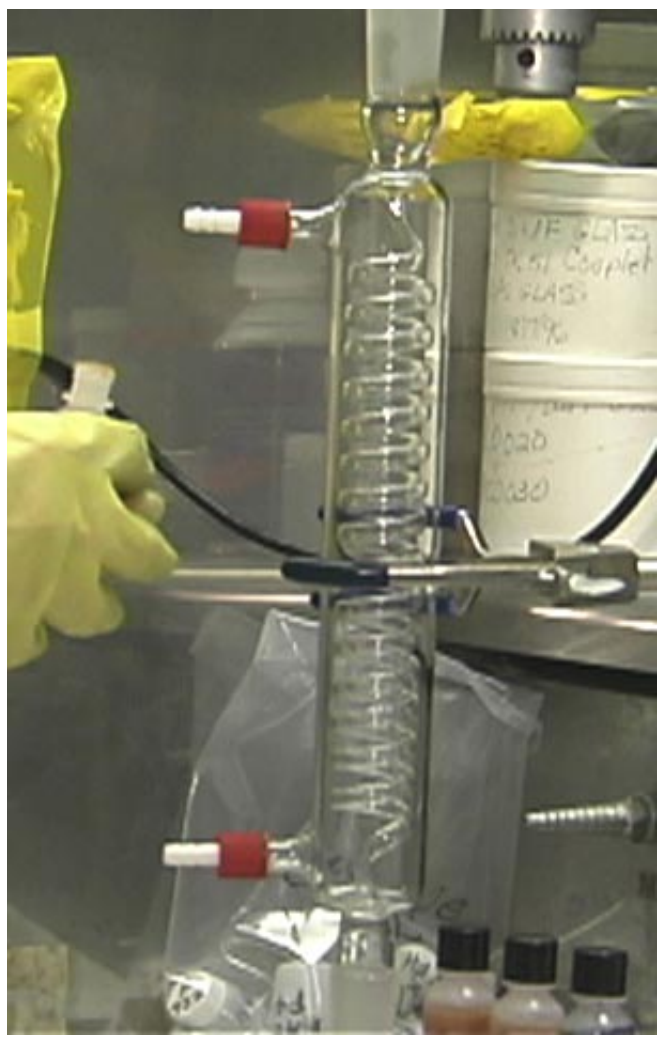

Figure 16. The Slurry "Racetrack".

Using $30 \mathrm{~mL}$ of each of the slurries, we timed how long it took for the whole amount to go through the glass column. Each slurry was well mixed before pouring into the column. Each slurry run was done in duplicate, and the column was cleaned between each run.

\begin{tabular}{|l|c|}
\hline Sample & Time (s) \\
\hline Baseline & 5.6 \\
\hline 3.3 M Nitrate & 5.9 \\
\hline 3.85 M Nitrate & 6.3 \\
\hline Manganese & $>480$ (est.) \\
\hline
\end{tabular}

For the DU slurries, the time to pass through the column was about the same, with the time increasing as the nitrate content increased. In

the case of the manganese slurry, four minutes had passed by the time the slurry front had reached about halfway through the column. While this is not a rigorous test, it does illustrate the relative flow characteristics of each of the slurries. In this case, the manganese shows extremely poor flow.

For a more detailed explanation of the rheology data, refer to the full report. ${ }^{17}$

\subsection{Conclusions}


WSRC-TR-2002-00029

- The baseline experiments (\#1 and \#2) - involving addition of caustic and depleted uranium to the legacy material and the enhanced nitrate experiment (\#8) involving addition of caustic, depleted uranium, and additional nitrate to the legacy material both achieve a total alpha removal sufficient to satisfy the Saltstone limits of 18 $\mathrm{nCi} / \mathrm{g}$.

- The presence of depleted uranium gives a benefit to alpha removal of $\sim 2 \mathrm{x}$.

- The largest reduction in soluble alpha activity results from the addition of caustic. Dilution inherent in the rest of the operations achieves the remaining decontamination.

- Use of sodium permanganate/formate, MST during neutralization, or iron instead of depleted uranium (Experiments \#4-\#6) offers no apparent benefit over the baseline processes.

- Addition of extra nitrate salts to a baseline experiment (\#8) provides the required decontamination and offers the advantage of less hydrogen generation by radiolysis.

- Over a dilution range of 2.3 to $11 \mathrm{x}$ for addition of the Am and $\mathrm{Cm}$ legacy material to Tank $51 \mathrm{H}$, we observed minimal evidence of leaching for alpha emitters from the solids. However, the net dilution that accompanies the transfer overwhelmed the small amount of leaching.

- These experiments are overall conservative compared to the tank farm operations that will occur. First, the dilutions in the tank farm will exceed those used in this study by a factor of $5 x$ or greater. Second, the total alpha activity data by counting includes a high bias, by an average factor of $\sim 4.5 \mathrm{x}$. Third, our demos may contain a low bias due to sorption of curium on the sample bottles by an average $\sim 1.15 \mathrm{x}$. Overall then, we would expect that alpha activities reported in the final samples may prove conservatively greater than those encountered in the tank farm by at least a factor of 4x, (with respect to our analytical biases).

- Considering that the mitigation flowsheets (i.e., permanganate, extra MST and iron for DU) show no effective benefit, SRTC recommends using the baseline or nitrate enhanced process. The use of either flowsheet should allow for Saltstone processing with a conservative margin. 
WSRC-TR-2002-00029

Appendix I. Prior Discards of Americium and Curium to the High Level Waste System

Prior discards of americium and curium at the Savannah River Site exceed the amounts planned for this disposal with the most recent discard occurring in 1991 from HCanyon. ${ }^{18}$ Today, Tank $39 \mathrm{H}$ contains a large fraction of the curium discarded at that time. Unfortunately, little reliable analytical data exists from the time of the transfer of the solution to the waste tank. Even after the long settling time in Tank $39 \mathrm{H}$, the material still poses processing concerns for the overall mission. The projected performance of the Salt Waste Processing Facility will not adequately treat the planned batches of waste coming from Tank $39 \mathrm{H}$ at nominal operating conditions. ${ }^{19}$ To address this concern, Roger Mahannah recently completed measurements of the actinides present within a sample of supernatant collected from the tank on July 8 (Robin Young to Samuel Fink et al., electronic mail message, August 22, 2001; sample density of $1.2361 \mathrm{~g} / \mathrm{mL}$ ). The following figure [ed. note: figure not shown] shows an extract from an electronic mail message (Roger Mahannah to Scott Federman et al., electronic mail message, August 16, 2001) summarizing the analyses for the sample designated by Lab Sample Number 200165176.*

\section{Cm-244 Result $\quad<2150 \mathrm{dpm} / \mathrm{ml}$}

CLAB does not routinely report '<' values for specific alpha emitting radionuclides. This sample was a special request. The following details the sample history and countroom work in $772-1 \mathrm{~F}$

The Tank 39 sample was introduced into the $772-1 \mathrm{~F}$ shielded cells where a dilution (approximately 1:10) was made on an aliquot of the sample to allow for removal from the cells. From this dilution, a secondary dilution was made to minimize the amount of salts that would be present on the alpha plate. Salts can interfere with the alpha counting method.

The overall dilution factor (DF) for the sample was

$$
1000 \mu \mathrm{L} / 10.24 \mathrm{~mL} / 500 \mathrm{~mL} / 10.5 \mathrm{~mL} / 100 \mu \mathrm{L}=2150
$$

To report a dpm value, I reviewed the alpha scan detector background data for several months to determine an average value. The average background in this detector for the $\mathrm{Cm}-244$ region was 0.5 count/10 min or $0.05 \mathrm{cpm}$.

\footnotetext{
* Robin Young notified the authors that the original message incorrectly identified the sample as LSN 156176 due to a typographical error by Mahannah.
} 
Because CLAB only uses these particular detectors to determine peak ratios, the detector efficiencies are not routinely determined. A standard was counted and determined the detector to be around $20 \%$ efficient. Therefore, our approximate detection limit would be $0.05 \mathrm{cpm} / 0.2=$ approx. $0.25 \mathrm{dpm}$ in the $\mathrm{Cm}-244$ region.

Based on the background data (169 data points) I reviewed to come up with the $0.05 \mathrm{cpm}$, the uncertainty was $0.05 \mathrm{cpm} \pm 0.08 \mathrm{cpm} @ 1$ sigma. For conservatism I rounded this number up to $(0.05+0.16$ [@2 sigma] $)$ cpm/ 0.2 or approx. $1 \mathrm{dpm}$. At $1 \mathrm{dpm} x$ the DF of 2150 you obtain the $<2150 \mathrm{dpm} / \mathrm{mL}$ answer.

The typical sample activities in CLAB routine samples are sufficiently high, that detector backgrounds, although checked every 6 hours, are primarily monitored to ensure a detector is not contaminated. The long term background is not routinely characterized nor is the variation in the background routinely determined for these detectors. Fortunately, most CLAB samples do not have $\mathrm{Cm}-244$, therefore the background in that region is low.

Vernon Jones analyzed the same sample using ICP-MS (Vernon Jones to Robin Young et al., electronic mail message, September 6, 2001). The ICP-MS analysis has a detection limit of $12 \mu \mathrm{g} / \mathrm{L}$ for mass number 244 and the measurement did not observe any Cm-244 present in the sample. The radiochemical counting method discussed above thus has a lower detection limit and found a ${ }^{244} \mathrm{Cm}$ concentration below $0.012 \mu \mathrm{g} / \mathrm{L}$ (or $1.2 \mathrm{nCi} / \mathrm{g}$ ). Hence, the curium content of the Tank $39 \mathrm{H}$ material would meet requirements for disposal through the Saltstone Production Facility assuming no other significant contribution from other alpha emitting actinides. 
WSRC-TR-2002-00029

Appendix II. Composition of the Multi-Tank Composite \#1.

The multi-tank composite \#1 was $~ 1 \mathrm{~L}$ of a sludge derived from a variety of tanks and stored in the high activity cells for several years before our use. Duplicate samples of this black slurry showed that it was $30 \mathrm{wt} \%$ in solids. A sample of the supernate was removed and sent to ADS for analyses. The results are as follows:

\begin{tabular}{|c|c|c|c|}
\hline Analysis & Result & Analysis & Result \\
\hline ICP-ES (mg/L) & & Counting $(\mathrm{dpm} / \mathrm{mL})$ & \\
\hline $\mathrm{Al}$ & 3 & $\mathrm{Pu}-239 / 240$ & $6.74 \mathrm{E}+01$ \\
\hline $\mathrm{B}$ & 2 & $\mathrm{Pu}-238$ & $6.33 \mathrm{E}+02$ \\
\hline $\mathrm{Ba}$ & 1 & $\mathrm{Pu}-241$ & $9.81 \mathrm{E}+02$ \\
\hline $\mathrm{Ca}$ & 1710 & Total Alpha & $1.84 \mathrm{E}+06$ \\
\hline $\mathrm{Cd}$ & 46 & Total Gamma & $3.92 \mathrm{E}+06$ \\
\hline $\mathrm{Co}$ & $<0.2(\mathrm{DL})$ & ICP-MS (mg/L) & \\
\hline $\mathrm{Cr}$ & 1 & mass 232 & $<0.000055(\mathrm{DL})$ \\
\hline $\mathrm{Cu}$ & $<1(\mathrm{DL})$ & mass 233 & 0.0112 \\
\hline $\mathrm{Fe}$ & 3 & mass 234 & 0.0175 \\
\hline $\mathrm{La}$ & 1 & mass 235 & 0.501 \\
\hline $\mathrm{Li}$ & 2 & mass 236 & 0.0449 \\
\hline $\mathrm{Mg}$ & 691 & mass 237 & 0.0119 \\
\hline $\mathrm{Mn}$ & 5 & mass 238 & 93.1 \\
\hline Mo & $<1(\mathrm{DL})$ & mass 239 & 0.0099 \\
\hline $\mathrm{Na}$ & 60100 & mass 240 & $<0.000055(\mathrm{DL})$ \\
\hline $\mathrm{Ni}$ & 1 & mass 241 & $<0.000055(\mathrm{DL})$ \\
\hline $\mathrm{P}$ & 2 & mass 242 & $<0.000055(\mathrm{DL})$ \\
\hline $\mathrm{Pb}$ & $<2$ & mass 243 & $<0.000055(\mathrm{DL})$ \\
\hline $\mathrm{Si}$ & 9 & mass 244 & $<0.000055(\mathrm{DL})$ \\
\hline $\mathrm{Sn}$ & 1 & mass 245 & $<0.000055(\mathrm{DL})$ \\
\hline $\mathrm{Sr}$ & 5 & mass 246 & $<0.000055(\mathrm{DL})$ \\
\hline $\mathrm{Ti}$ & $<0.1(\mathrm{DL})$ & mass 247 & $<0.000055(\mathrm{DL})$ \\
\hline $\mathrm{V}$ & 0.2 & & \\
\hline $\mathrm{Zn}$ & 0.3 & Wt. \% Solids & $30.3 \%$ \\
\hline $\mathrm{Zr}$ & $<0.2(\mathrm{DL})$ & & \\
\hline
\end{tabular}


WSRC-TR-2002-00029

Appendix II, continued

\begin{tabular}{|c|c|}
\hline \multicolumn{2}{|c|}{ ICP-MS, fission products } \\
\hline Element & Conc. $(\mathrm{mg} / \mathrm{L})$ \\
\hline $\mathrm{Zr}$ & $0.00 \mathrm{E}+00$ \\
\hline $\mathrm{Tc}-99$ & $1.55 \mathrm{E}+00$ \\
\hline $\mathrm{Mo}$ & $0.00 \mathrm{E}+00$ \\
\hline $\mathrm{Ag}$ & $4.54 \mathrm{E}+00$ \\
\hline $\mathrm{Pd}$ & $7.35 \mathrm{E}+00$ \\
\hline $\mathrm{Rh}$ & $1.27 \mathrm{E}+00$ \\
\hline $\mathrm{Ru}$ & $3.66 \mathrm{E}+00$ \\
\hline $\mathrm{Cd}$ & $4.05 \mathrm{E}+01$ \\
\hline $\mathrm{Sn}$ & $0.00 \mathrm{E}+00$ \\
\hline $\mathrm{La}$ & $0.00 \mathrm{E}+00$ \\
\hline $\mathrm{Ce}$ & $0.00 \mathrm{E}+00$ \\
\hline $\mathrm{W}$ & $0.00 \mathrm{E}+00$ \\
\hline $\mathrm{Re}$ & $0.00 \mathrm{E}+00$ \\
\hline $\mathrm{Os}$ & $0.00 \mathrm{E}+00$ \\
\hline $\mathrm{Ir}$ & $0.00 \mathrm{E}+00$ \\
\hline $\mathrm{Pt}$ & $3.43 \mathrm{E}-02$ \\
\hline $\mathrm{Au}$ & $5.44 \mathrm{E}-02$ \\
\hline $\mathrm{Hg}$ & $2.63 \mathrm{E}+01$ \\
\hline $\mathrm{Pb}$ & $0.00 \mathrm{E}+00$ \\
\hline
\end{tabular}


WSRC-TR-2002-00029

Appendix III. Composition of the Multi-Tank Composite \#2.

The material for multi-tank composite \#2 was derived from several samples from tanks 40 and 51. A total of $\sim 90 \mathrm{~mL}$ of composite was made. A sample of the supernatant liquid was sent to ADS for analyses. The results are as follows:

\begin{tabular}{|c|c||c|c|}
\hline Analysis & \multicolumn{1}{|c|}{ Result } & Analysis & Result \\
\hline ICP-ES (mg/L) & & ICP-ES (mg/L) & \\
\hline $\mathrm{Ag}$ & $2.09 \mathrm{E}-02$ & $\mathrm{P}$ & $2.01 \mathrm{E}+00$ \\
\hline $\mathrm{Al}$ & $5.60 \mathrm{E}+01$ & $\mathrm{~Pb}$ & $1.91 \mathrm{E}-01$ \\
\hline $\mathrm{B}$ & $2.61 \mathrm{E}-01$ & $\mathrm{Si}$ & $2.04 \mathrm{E}+00$ \\
\hline $\mathrm{Ba}$ & $1.04 \mathrm{E}-02$ & $\mathrm{Sn}$ & $1.57 \mathrm{E}-01$ \\
\hline $\mathrm{Ca}$ & $1.47 \mathrm{E}-01$ & $\mathrm{Sr}$ & $4.89 \mathrm{E}-03$ \\
\hline $\mathrm{Cd}$ & $1.19 \mathrm{E}-02$ & $\mathrm{Ti}$ & $4.89 \mathrm{E}-03$ \\
\hline $\mathrm{Co}$ & $3.00 \mathrm{E}-02$ & $\mathrm{~V}$ & $2.67 \mathrm{E}-02$ \\
\hline $\mathrm{Cr}$ & $2.88 \mathrm{E}+00$ & $\mathrm{Zn}$ & $1.83 \mathrm{E}-02$ \\
\hline $\mathrm{Cu}$ & $8.39 \mathrm{E}-03$ & $\mathrm{Zr}$ & $9.78 \mathrm{E}-03$ \\
\hline $\mathrm{Fe}$ & $2.91 \mathrm{E}-02$ & & \\
\hline $\mathrm{La}$ & $5.72 \mathrm{E}-02$ & Total Alpha (nCi/g) & 218 \\
\hline $\mathrm{Li}$ & $3.43 \mathrm{E}-02$ & & \\
\hline $\mathrm{Mg}$ & $1.66 \mathrm{E}-02$ & Wt. \% Ins. Solids & 10.5 \\
\hline $\mathrm{Mn}$ & $6.67 \mathrm{E}-03$ & & \\
\hline $\mathrm{Mo}$ & $1.18 \mathrm{E}-01$ & Free OH (M) & $2.37 \mathrm{E}-02$ \\
\hline $\mathrm{Na}$ & $1.47 \mathrm{E}+03$ & & \\
\hline $\mathrm{Ni}$ & $4.06 \mathrm{E}-02$ & Cs137 (dpm/mL) & $1.82 \mathrm{E}+06$ \\
\hline
\end{tabular}


WSRC-TR-2002-00029

Appendix IV. Slurry Composition During the Aging Process.

Each experiment that had an aging step (\#1-\#6, \#8) combined neutralized Am/Cm solution to a multi-tank sludge composite, and finally had salts added. The addition of the salts adjusted the resulting supernatant liquid similar to that in Tank $51 \mathrm{H}$ with respect to nitrite, sulfate and carbonate. Nitrate and free hydroxide amounts were not altered.

Experiment \#1 (baseline)

$50 \mathrm{~mL}$ of the Am/Cm caustic slurry (see section 4.2$)$ was added to $81.9 \mathrm{~mL}(94.2 \mathrm{~g}$ ) of the multi-tank composite slurry, generating $132 \mathrm{~mL}$ of a new composite slurry. To this was added $3.20 \mathrm{~g}$ of $\mathrm{Na}_{2} \mathrm{CO}_{3}, 4.45 \mathrm{~g}$ of $\mathrm{NaNO}_{2}$, and $2.75 \mathrm{~g}$ of $\mathrm{Na}_{2} \mathrm{SO}_{4}$.

Experiment \#2 (baseline duplicate)

$50 \mathrm{~mL}$ of the Am/Cm caustic slurry (see section 4.2$)$ was added to $81.9 \mathrm{~mL}(94.2 \mathrm{~g}$ ) of the multi-tank composite slurry, generating $132 \mathrm{~mL}$ of a new composite slurry. To this was added $3.20 \mathrm{~g}$ of $\mathrm{Na}_{2} \mathrm{CO}_{3}, 4.45 \mathrm{~g}$ of $\mathrm{NaNO}_{2}$, and $2.75 \mathrm{~g}$ of $\mathrm{Na}_{2} \mathrm{SO}_{4}$.

Experiment \#3 (baseline, no DU)

$50 \mathrm{~mL}$ of the Am/Cm caustic slurry (see section 4.3 ) was added to $23.5 \mathrm{~mL}(27.0 \mathrm{~g}$ ) of the multi-tank composite slurry, generating $73.5 \mathrm{~mL}$ of a new composite slurry. To this was added $1.82 \mathrm{~g}$ of $\mathrm{Na}_{2} \mathrm{CO}_{3}, 2.54 \mathrm{~g}$ of $\mathrm{NaNO}_{2}$, and $1.57 \mathrm{~g}$ of $\mathrm{Na}_{2} \mathrm{SO}_{4}$.

Experiment \#4 (permanganate)

$50 \mathrm{~mL}$ of the Am/Cm caustic slurry (see section 4.4 ) was added to $81.9 \mathrm{~mL}(94.2 \mathrm{~g}$ ) of the multi-tank composite slurry, generating $132 \mathrm{~mL}$ of a new composite slurry. To this was added $3.27 \mathrm{~g}$ of $\mathrm{Na}_{2} \mathrm{CO}_{3}, 4.55 \mathrm{~g}$ of $\mathrm{NaNO}_{2}$, and $2.81 \mathrm{~g}$ of $\mathrm{Na}_{2} \mathrm{SO}_{4}$.

Experiment \#5 (MST)

$50 \mathrm{~mL}$ of the Am/Cm caustic slurry (see section 4.5 ) was added to $81.9 \mathrm{~mL}(94.2 \mathrm{~g}$ ) of the multi-tank composite slurry, generating $132 \mathrm{~mL}$ of a new composite slurry. To this was added $3.27 \mathrm{~g}$ of $\mathrm{Na}_{2} \mathrm{CO}_{3}, 4.55 \mathrm{~g}$ of $\mathrm{NaNO}_{2}$, and $2.81 \mathrm{~g}$ of $\mathrm{Na}_{2} \mathrm{SO}_{4}$.

Experiment \#6 (iron for DU)

$50 \mathrm{~mL}$ of the $\mathrm{Am} / \mathrm{Cm}$ caustic slurry (see section 4.6$)$ was added to $81.9 \mathrm{~mL}(94.2 \mathrm{~g}$ ) of the multi-tank composite slurry, generating $132 \mathrm{~mL}$ of a new composite slurry. To this was added $5.38 \mathrm{~g}$ of $\mathrm{Na}_{2} \mathrm{CO}_{3}, 7.64 \mathrm{~g}$ of $\mathrm{NaNO}_{2}$, and $4.62 \mathrm{~g}$ of $\mathrm{Na}_{2} \mathrm{SO}_{4}$.

Experiment \#8 (baseline + nitrate)

$30 \mathrm{~mL}$ of the Am/Cm caustic slurry (see section 4.7) was added to $90 \mathrm{~mL}(115 \mathrm{~g}$ ) of the multi-tank composite slurry, generating $120 \mathrm{~mL}$ of a new composite slurry. To this was added $2.98 \mathrm{~g}$ of $\mathrm{Na}_{2} \mathrm{CO}_{3}, 4.14 \mathrm{~g}$ of $\mathrm{NaNO}_{2}$, and $2.56 \mathrm{~g}$ of $\mathrm{Na}_{2} \mathrm{SO}_{4}$. 
Appendix V. Analysis of the Acidic Am/Cm Solution As Received.

\begin{tabular}{|c|c|c|c|}
\hline Analysis & Result & Analysis & Result \\
\hline free acid & 5.97 & $\mathrm{~V}(\mathrm{M})$ & 0.000884 \\
\hline $\mathrm{PH}$ & 2.22 & $\mathrm{Zn}(\mathrm{M})$ & 0.000688 \\
\hline Ion Chromat. & & $\mathrm{Zr}(\mathrm{M})$ & 0.000727 \\
\hline $\mathrm{Cl}^{-}(\mathrm{M})$ & $<0.563(\mathrm{DL})$ & Counting & \\
\hline $\mathrm{F}^{-}(\mathrm{M})$ & $<1.05(\mathrm{DL})$ & Cs-137 (dpm/mL) & $3.15 \mathrm{E}+08$ \\
\hline $\mathrm{HCO}^{-}(\mathrm{M})$ & $<2.22(\mathrm{DL})$ & Eu-154 (dpm/mL) & $1.23 \mathrm{E}+09$ \\
\hline $\mathrm{NO}^{-}(\mathrm{M})$ & 6.37 & Eu-155 (dpm/mL) & $1.74 \mathrm{E}+08$ \\
\hline $\mathrm{NO}^{-}(\mathrm{M})$ & $<2.17(\mathrm{DL})$ & Am-241 (dpm/mL) & $3.34 \mathrm{E}+08$ \\
\hline $\mathrm{C}_{2} \mathrm{O}^{2-}(\mathrm{M})$ & $<1.14(\mathrm{DL})$ & Am-243/Np-239 & $4.27 \mathrm{E}+08$ \\
\hline $\mathrm{PO}^{3-}(\mathrm{M})$ & $<1.05(\mathrm{DL})$ & Total Gamma & $2.48 \mathrm{E}+09$ \\
\hline $\mathrm{SO}^{2-}(\mathrm{M})$ & $<0.521(\mathrm{DL})$ & $\mathrm{Cm}-244(\mathrm{dpm} / \mathrm{mL})$ & $3.14 \mathrm{E}+10$ \\
\hline Atomic Abs. & & Am243/Pu239/240 & $3.20 \mathrm{E}+08$ \\
\hline $\mathrm{Na}(\mathrm{M})$ & 0.0656 & $\mathrm{Pu} 238 / \mathrm{Am} 241$ & $3.20 \mathrm{E}+08$ \\
\hline ICP-ES & & Total Alpha & $3.20 \mathrm{E}+10$ \\
\hline $\mathrm{Al}(\mathrm{M})$ & 0.0679 & PuTTa & \\
\hline $\mathrm{B}(\mathrm{M})$ & $<0.00278(\mathrm{DL})$ & $\mathrm{Pu}-238(\mathrm{dpm} / \mathrm{mL})$ & $2.35 \mathrm{E}+08$ \\
\hline $\mathrm{Ba}(\mathrm{M})$ & $<0.000219(\mathrm{DL})$ & $\mathrm{Pu} 239 / 240$ & $8.25 \mathrm{E}+07$ \\
\hline $\mathrm{Ca}(\mathrm{M})$ & $<0.000249$ (DL) & $\mathrm{Pu}-241(\mathrm{dpm} / \mathrm{mL})$ & $<1.26 \mathrm{E}+07(\mathrm{DL})$ \\
\hline $\mathrm{Cd}(\mathrm{M})$ & $<0.000179(\mathrm{DL})$ & ICP-MS & \\
\hline $\mathrm{Co}(\mathrm{M})$ & $<0.000509$ (DL) & mass $232(\mathrm{mg} / \mathrm{L})$ & 0.755 \\
\hline $\mathrm{Cr}(\mathrm{M})$ & 0.0177 & mass $233(\mathrm{mg} / \mathrm{L})$ & $<0.116(\mathrm{DL})$ \\
\hline $\mathrm{Cu}(\mathrm{M})$ & 0.000582 & mass $234(\mathrm{mg} / \mathrm{L})$ & 2.64 \\
\hline $\mathrm{Fe}(\mathrm{M})$ & 0.167 & mass $235(\mathrm{mg} / \mathrm{L})$ & 1.59 \\
\hline $\mathrm{La}(\mathrm{M})$ & 0.00962 & mass $236(\mathrm{mg} / \mathrm{L})$ & 0.500 \\
\hline $\mathrm{Li}(\mathrm{M})$ & 0.0638 & mass $237(\mathrm{mg} / \mathrm{L})$ & 2.64 \\
\hline $\operatorname{Mg}(\mathrm{M})$ & 0.000535 & mass $238(\mathrm{mg} / \mathrm{L})$ & 833 \\
\hline $\operatorname{Mn}(\mathrm{M})$ & 0.00670 & mass $239(\mathrm{mg} / \mathrm{L})$ & 3.61 \\
\hline Mo (M) & 0.000469 & mass $240(\mathrm{mg} / \mathrm{L})$ & 125 \\
\hline $\mathrm{Na}(\mathrm{M})$ & 0.0736 & mass $241(\mathrm{mg} / \mathrm{L})$ & 38.5 \\
\hline $\mathrm{Ni}(\mathrm{M})$ & 0.0106 & mass $242(\mathrm{mg} / \mathrm{L})$ & 6.14 \\
\hline $\mathrm{P}(\mathrm{M})$ & $<0.0113$ & mass $243(\mathrm{mg} / \mathrm{L})$ & 770 \\
\hline $\mathrm{Pb}(\mathrm{M})$ & $<0.00222(\mathrm{DL})$ & mass $244(\mathrm{mg} / \mathrm{L})$ & 173 \\
\hline $\mathrm{Si}(\mathrm{M})$ & 0.0453 & mass $245(\mathrm{mg} / \mathrm{L})$ & 9.57 \\
\hline $\operatorname{Sn}(\mathrm{M})$ & $<0.00134(\mathrm{DL})$ & mass $246(\mathrm{mg} / \mathrm{L})$ & 7.93 \\
\hline $\mathrm{Sr}(\mathrm{M})$ & $<0.000114(\mathrm{DL})$ & mass $247(\mathrm{mg} / \mathrm{L})$ & 0.140 \\
\hline $\mathrm{Ti}(\mathrm{M})$ & 0.000438 & Density (g/mL) & 1.232 \\
\hline
\end{tabular}


WSRC-TR-2002-00029

Appendix V, continued

\begin{tabular}{|c|c|}
\hline \multicolumn{2}{|c|}{ ICP-MS, fission products } \\
\hline Element & Conc. $(\mathrm{mg} / \mathrm{L})$ \\
\hline $\mathrm{Zr}$ & $0.00 \mathrm{E}+00$ \\
\hline $\mathrm{Tc}-99$ & $2.66 \mathrm{E}+00$ \\
\hline $\mathrm{Mo}$ & $2.57 \mathrm{E}+01$ \\
\hline $\mathrm{Ag}$ & $2.32 \mathrm{E}+00$ \\
\hline $\mathrm{Pd}$ & $5.06 \mathrm{E}+00$ \\
\hline $\mathrm{Rh}$ & $2.89 \mathrm{E}+00$ \\
\hline $\mathrm{Ru}$ & $1.12 \mathrm{E}+02$ \\
\hline $\mathrm{Cd}$ & $2.39 \mathrm{E}+00$ \\
\hline $\mathrm{Sn}$ & $2.81 \mathrm{E}-01$ \\
\hline $\mathrm{La}$ & $1.23 \mathrm{E}+03$ \\
\hline $\mathrm{Ce}$ & $1.74 \mathrm{E}+03$ \\
\hline $\mathrm{W}$ & $2.61 \mathrm{E}-01$ \\
\hline $\mathrm{Re}$ & $0.00 \mathrm{E}+00$ \\
\hline $\mathrm{Os}$ & $0.00 \mathrm{E}+00$ \\
\hline $\mathrm{Ir}$ & $0.00 \mathrm{E}+00$ \\
\hline $\mathrm{Pt}$ & $0.00 \mathrm{E}+00$ \\
\hline $\mathrm{Au}$ & $0.00 \mathrm{E}+00$ \\
\hline $\mathrm{Hg}$ & $6.63 \mathrm{E}+02$ \\
\hline $\mathrm{Pb}$ & $6.99 \mathrm{E}+00$ \\
\hline
\end{tabular}


WSRC-TR-2002-00029

Appendix VI. Total Data Set.

This appendix shows the total alpha activity for each step of each of the experiments.

Units are $\mathrm{nCi} / \mathrm{g}$.

\begin{tabular}{|l|c|c|c|c|c|c|c|}
\hline & Baseline 1 & Baseline 2 & no DU & MnO $^{-}$ & MST & Ferric & $\begin{array}{c}\text { Enhanced } \\
\text { Nitrate }\end{array}$ \\
\hline Initial & $1.17 \mathrm{E}+07$ & $1.17 \mathrm{E}+07$ & $1.17 \mathrm{E}+07$ & $1.17 \mathrm{E}+07$ & $1.17 \mathrm{E}+07$ & $1.17 \mathrm{E}+07$ & $1.17 \mathrm{E}+07$ \\
Neutralized 1 & 64.7 & 89.7 & 178 & 45.5 & 52.4 & 59.4 & 116 \\
Aging 1 & 83.1 & 81.9 & 78.2 & 97.5 & 121 & 89.7 & 81.5 \\
Aging 2 & 95 & 127 & 164 & 107 & 203 & 173 & 117 \\
Aging 3 & 72.1 & 53.6 & 144 & 153 & 504 & 201 & 71.3 \\
Aging 4 & 76.6 & 81.1 & 139 & 219 & 770 & 317 & 85.2 \\
Decants \& & 29.6 & 37.3 & 63.5 & 49.1 & 197 & 108 & 41.9 \\
washes & & & & & & & \\
MST 1 (24 h) & 8.35 & 10.1 & 43 & 36.7 & 49.1 & 36.6 & 8.19 \\
MST 2 (1 wk) & 11.9 & 17.6 & 41.8 & 10.1 & 18.4 & 22.5 & 2.03 \\
& & & & & & & \\
Long Term & & & & & & & \\
Neutralized 2 & 93 & 122 & 172 & 112 & 1540 & 94.6 & NA \\
Neutralized 3 & 61 & 80.3 & 102 & 73.7 & 61.4 & 67.6 & NA \\
Aging 5 & 18.8 & 14.8 & 12.4 & 8.39 & 71.3 & 33.6 & NA \\
Aging 6 & 3.61 & 8.97 & 32.3 & 13.2 & 76.2 & 63.1 & NA \\
Aging 7 & 14.7 & 14 & 938 & NA & NA & NA & NA \\
MST 3 & 15.5 & 29.9 & 114 & 20.6 & 10.4 & 21.6 & NA \\
\hline
\end{tabular}


Appendix VII. Analytical Data Biases.

There are two analytical biases in our reported total alpha activity. Despite the presence of these biases, we report the data as is. To assess the implications on the disposal operations, we determined the magnitude of these two biases.

First, we chose to use a series of samples we previously submitted from Experiment \#4 (Permanganate). We chose a single sample each from the neutralization, aging, washing and MST treatment steps.

We know that the presence of beta and gamma emitters in our samples can bias our total alpha results high. To determine the range of the bias, ADS personnel performed a typical alpha PHA on each of these samples to determine the total alpha activity. Then, personnel performed a cesium chemical stripping on these samples followed by another alpha PHA.

\begin{tabular}{|l|c|c|c|}
\hline \multicolumn{1}{|c|}{ Sample } & w/cesium $(\mathrm{dpm} / \mathrm{mL})$ & wo/cesium $(\mathrm{dpm} / \mathrm{mL})$ & Ratio $(\mathrm{w} v s$ wo $)$ \\
\hline Neutralization & $1.64 \mathrm{E}+05$ & $3.00 \mathrm{E}+04$ & 5.47 \\
\hline Aging & $3.24 \mathrm{E}+05$ & $1.29 \mathrm{E}+05$ & 2.51 \\
\hline Washing & $1.27 \mathrm{E}+05$ & $5.44 \mathrm{E}+04$ & 2.33 \\
\hline MST Treatment & $3.07 \mathrm{E}+04$ & $3.75 \mathrm{E}+03$ & 8.19 \\
\hline
\end{tabular}

These results show that after stripping the cesium, the total alpha result drops by an average factor of $\sim 4.5$ across all the samples.

During the later stages of the experiments, a QA experiment showed that the plastic bottles may adsorb curium from the samples. Adsorption would bias our total alpha activity low. To determine the range of the bias, personnel performed a series of experiments on the same material from four samples we used above. First, the remaining material in each of the four sample bottles was acidified using $2 \mathrm{M}$ nitric acid (any dilutions were accounted for in the results) and analyzed using an alpha PHA. Acidifying the material in the bottle will pull any adsorbed material from the walls of the bottle. Then, some of this material was chemically stripped of cesium, and analyzed again with an alpha PHA. The results follow.

\begin{tabular}{|l|c|c|}
\hline \multicolumn{1}{|c|}{ Sample } & w/cesium $(\mathrm{dpm} / \mathrm{mL})$ & wo/cesium $(\mathrm{dpm} / \mathrm{mL})$ \\
\hline Neutralization & $1.47 \mathrm{E}+05$ & $3.14 \mathrm{E}+04$ \\
\hline Aging & $3.86 \mathrm{E}+05$ & $1.32 \mathrm{E}+05$ \\
\hline Washing & $1.36 \mathrm{E}+05$ & $6.15 \mathrm{E}+04$ \\
\hline MST Treatment & $4.64 \mathrm{E}+04$ & $5.18 \mathrm{E}+03$ \\
\hline
\end{tabular}


WSRC-TR-2002-00029

The "without cesium" result was then compared to the "without cesium" result of the samples that were not acidified in the bottle.

\begin{tabular}{|l|c|c|c|}
\hline \multicolumn{1}{|c|}{ Sample } & $\begin{array}{c}\text { wo/cesium }(\mathrm{dpm} / \mathrm{mL}) \\
\text { caustic }\end{array}$ & $\begin{array}{c}\text { wo/cesium }(\mathrm{dpm} / \mathrm{mL}) \\
\text { acidified }\end{array}$ & $\begin{array}{c}\text { Ratio } \\
\text { (acid } v s \text { caustic) }\end{array}$ \\
\hline Neutralization & $3.00 \mathrm{E}+04$ & $3.14 \mathrm{E}+04$ & 1.05 \\
\hline Aging & $1.29 \mathrm{E}+05$ & $1.32 \mathrm{E}+05$ & 1.02 \\
\hline Washing & $5.44 \mathrm{E}+04$ & $6.15 \mathrm{E}+04$ & 1.13 \\
\hline MST Treatment & $3.75 \mathrm{E}+03$ & $5.18 \mathrm{E}+03$ & 1.38 \\
\hline
\end{tabular}

We compare the cesium-stripped samples as they are more analytically accurate.

The results of this comparison show that on average the acidified samples (which will contain any material adsorbed onto the bottle surfaces) are biased low by a factor of $\sim 1.15$ across these samples.

In total, if one accounts for the $\sim 4.5$ factor high bias, and the $\sim 1.15$ factor low bias, we can conclude that our results are biased high by an approximate overall factor of 4 . 
WSRC-TR-2002-00029

\section{REFERENCES}

${ }^{1}$ I. M. MacAfee, to P. L. Roggenkamp, "Historical Pu Irradiations", DPST-87-346, March 18, 1987.

${ }^{2}$ A. P. Gouge, "Disposition of F-Canyon Am-Cm, Analysis of Disposition Options", NMP-ESE-940020, Rev. 1, July 13, 1994.

${ }^{3}$ C. C. Mason, to W. H. Britton, Letter, "Disposition of Americium (Am) - Curium Solution in the FCanyon", August 26, 1993.

${ }^{4}$ D. A. Berry, "Disposition of Am/Cm Materials Through the High Level Waste System", G-ESR-G00039, May 1, 2001.

${ }^{5}$ The Chemistry of the Actinide Elements, Volume 2, Ed. J. J. Katz, G. T. Seaborg, L. R. Moss, Chapman and Hall, 1986, pg. 962-988.

${ }^{6}$ D. T. Hobbs, "Solubility of Americium and Curium in Alkaline Solutions", WSRC-TR-94-0252, June 1, 1994.

${ }^{7}$ V. F. Peretrukhin, V. P. Shilov, A. K. Pikaev, and C. Delegard, "Alkaline Chemistry of Transuranic Elements and Technetium and the Treatment of Alkaline Radioactive Wastes," WHC-EP-0817, May 1995.

${ }^{8}$ V. F. Peretrukhin, V. I. Silin, A. V. Kareta, A. V. Gelis, V. P. Shilov, K. E. German, E. V. Firsova, A. G. Maslennikov, and V. E. Trushina, "Purification of Alkaline Solutions and Wastes from Actinides and Technetium by Coprecipitation with Some Carriers Using the Method of Appearing Reagents: Final Report," PNNL-11988, September 1998.

${ }^{9}$ M. S. Miller, Technical Task Request: Am/Cm, Sample Analysis and Removal Efficiency, HLE-TTR2001-052, Rev 0, May 4, 2001.

${ }^{10}$ B. A. Davis, "Waste Acceptance Criteria for High Level Liquid Waste Transfers to the 241-F/H Tank Farms," X-SD-G-00001, Rev. 12, July 2001.

${ }^{11}$ E. D. Lee, "Waste Pretreatment Facility Waste Acceptance Criteria for Waste Entering the Extended Sludge Processing Tanks 40, 42, and 51", X-SD-H-00001, Rev. 1, November 2000.

${ }^{12}$ M. A. Rious-Armstrong, "Waste Acceptance Criteria for Extended Sludge Processing Transfers to DWPF", X-SD-G-00004, Rev. 3, November 2001.

${ }^{13}$ D. T. Hobbs, "Phase V Simulant Testing of Monosodium Titanate Adsorption", WSRC-TR-2000-00142, May 22, 2000.

${ }^{14}$ D. D. Walker and N. E. Bibler, "The Dependence of Radiolytic $\mathrm{H}_{2}$ Generation on the Nitrate Concentration in High-Level Waste Solutions," WSRC-RP-91-1171, November 19, 1991.

${ }^{15}$ S. G. Loftin, "Proposed Flowsheet To Send Am/Cm Material From F-Canyon To High Level Waste" NMM-ETS-2001-00101, June 13, 2001.

16 "Savannah River Site High Level Waste System Plan: Revision 12," HLW-2001-00040, March 2001.

${ }^{17}$ D. C. Koopman, "Evaluation of the Rheological properties of four Americium-curium Flowsheet Slurries", SRT-GPD-2001-00093, October 22, 2001.

${ }^{18}$ Test Authorization, "Recovery of Pu-242 from Mark 42 Assemblies," WSRC-OX-89-40-001, October 9, 1990.

${ }^{19}$ H. H. Elder, "Salt Blending Basis for Revision 12 of the HLW System Plan," HLW-SDT-2001-00146, Rev. 0, April 26, 2001. 